University of Nebraska - Lincoln

DigitalCommons@University of Nebraska - Lincoln

Publications from USDA-ARS / UNL Faculty

U.S. Department of Agriculture: Agricultural

Research Service, Lincoln, Nebraska

2005

Ammonia: Measurement Issues

Lowry A. Harper

USDA-ARS

Follow this and additional works at: https://digitalcommons.unl.edu/usdaarsfacpub

Harper, Lowry A., "Ammonia: Measurement Issues" (2005). Publications from USDA-ARS / UNL Faculty. 1339.

https://digitalcommons.unl.edu/usdaarsfacpub/1339

This Article is brought to you for free and open access by the U.S. Department of Agriculture: Agricultural Research Service, Lincoln, Nebraska at DigitalCommons@University of Nebraska - Lincoln. It has been accepted for inclusion in Publications from USDA-ARS / UNL Faculty by an authorized administrator of DigitalCommons@University of Nebraska - Lincoln. 


\title{
Ammonia: Measurement Issues
}

\author{
LOWRY A. HARPER \\ Southern Piedmont Conservation Research Unit \\ J. Phil Campbell, Sr., Natural Resources Conservation Center \\ USDA-ARS \\ Watkinsville, Georgia
}

Ammonia $\left(\mathrm{NH}_{3}\right)$ is a colorless gas under standard conditions, whose pungent odor is easily discernible at concentrations above about $10 \mathrm{ppm}$, and to some persons, down to almost $1 \mathrm{ppm}$. It is the major basic neutralizing gas in the atmosphere so it has an important role in the neutralization of atmospheric acids generated by the oxidation of sulfur dioxide $\left(\mathrm{SO}_{2}\right)$ and nitrogen oxides $\left(\mathrm{NO}_{\mathrm{x}}\right)$. As a result, the reaction product of $\mathrm{NH}_{3}$, ammonium $\left(\mathrm{NH}_{4}^{+}\right)$, forms an aerosol that is a major component of atmospheric aerosols and in precipitation (Asman et al., 1998). Other organic forms also exist, such as amines and organic N compounds (not currently studied), but the concentrations of these components are generally negligible by comparison (Van der Eerden, 1982).

Most $\mathrm{NH}_{3}$ is emitted near the earth's surface and a large proportion of these sources are of anthropogenic origin (Bouwman et al., 1997). Land-based $\mathrm{NH}_{3}$ emissions are mainly from agricultural production (Fig. 15-1.). These sources are numerous, have low source heights and are scattered both temporally and spatially. One anthropogenic component of Fig. $15-1$ not included is $\mathrm{NH}_{3}$ emissions from motor vehicles. Recent studies (Fraser \& Cass, 1998) found that automobile emissions in the South Coast Air Basin (surrounding Los Angeles, CA) were comparable to livestock waste emissions with about $15 \%$ each of the total emissions inventory (Russell et al.,1988; Dickson, 1991). A comparison of vehicle emissions in North Carolina (McColloch, 2001, personal communication) with emissions from swine production [using Harper et al. (2004a) emission factors] suggested that automobile emissions were about $28 \%$ of that from swine production. A reevaluation of nationwide anthropogenic emissions is needed with the increase in three-way or dual-bed catalytic converters (Fraser \& Cass, 1998) on vehicles, which are designed to reduce $\mathrm{N}$ oxides to the atmosphere.

There has been recognition of gas-phase $\mathrm{NH}_{3}$ since the 19th century but the interest was focused largely on its effect as a fertilizer (Lawes \& Gilbert, 1851). It was not until the mid 20th century that techniques were available to determine that plants emit and absorb $\mathrm{NH}_{3}$ in relation to an $\mathrm{NH}_{3}$ compensation point in plants (Meyer, 1973; Farquhar et al., 1983). Because of the ability of $\mathrm{NH}_{3}$ to react with measurement equipment, many of the early studies were somewhat inaccurate; however, noninvasive techniques were developed and used to evaluate net

Copyright @2005. American Society of Agronomy, Crop Science Society of America, Soil Science Society of America, 677 S. Segoe Rd., Madison, WI 53711, USA. Micrometeorology in Agricultural Systems, Agronomy Monograph no. 47. 


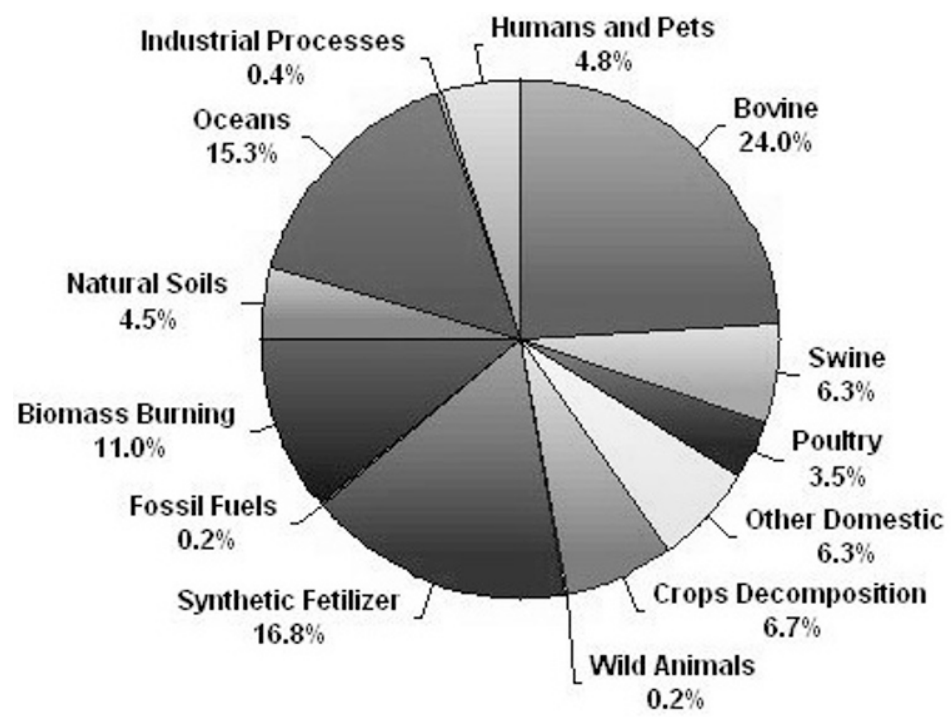

Fig. 15-1. Global ammonia emissions (after Bouwman et al., 1997) [Note: Ammonia emissions for vehicles are not included in this inventory.]

transport of $\mathrm{NH}_{3}$ in cropping systems (Denmead et al., 1978; Harper et al., 1983, 1987) and using these techniques, it was found that significant amounts of $\mathrm{NH}_{3}$ can be absorbed from the atmosphere under periods of diurnal and seasonal plant $\mathrm{N}$ stress.

The release of anthropogenic $\mathrm{NH}_{3}$ into the atmosphere has increased in many regions of the world, which has led to deposition of $\mathrm{N}$ downwind from major sources (Asman, 1994). Areas of high deposition may show forest decline (Nihlgard, 1985) and some estimates have suggested that atmospheric deposition may contribute 35 to $60 \%$ of the total $\mathrm{N}$ loading to some coastal waters (Paerl, 1995). Although $\mathrm{NH}_{3}$ is basic, it may still contribute toward acidification of ecosystems, as $1 \mathrm{~mol}$ of ammonium sulfate $\left(\mathrm{NH}_{4} \mathrm{SO}_{4}\right)$ can result in the release of 4 mol of hydrogen ions $\left(\mathrm{H}^{+}\right)$by nitrification (Van Breemen et al., 1982). Dry deposition of $\mathrm{NH}_{3}$ also can result in the release of one proton by nitrification. These concepts are, however, a simplification and the net acidification from atmospheric $\mathrm{NH}_{3}+\mathrm{NH}_{4}^{+}$is complex and will vary with respect to the nutrient status of the soil. Indeed, Galloway (1995) has suggested that $\mathrm{NH}_{3}$ emissions are, potentially, more acidifying than current emissions of $\mathrm{SO}_{2}$ or $\mathrm{NO}_{x}$ depositions.

Ammonia volatilization is a complex physical and chemical process (Freney et al., 1983) and emissions are generally related to four factors: $\mathrm{NH}_{4}^{+}$ concentration of the medium, temperature of the medium, $\mathrm{pH}$ (hydrogen ion concentration where $\left[\mathrm{H}^{+}\right]=1 \times 10^{-\mathrm{pH}}$ of the solution) of the medium, and turbulent transport of the $\mathrm{NH}_{3}$ from the medium. The chemical effect, the partial pressure of $\mathrm{NH}_{3}$ at the solution surface, may be explained as a function of Henrys law and the dissociation relationship of $\mathrm{NH}_{3}=\mathrm{NH}_{4}^{+}$, which can be expressed by the generalized relationship,

$p_{\left(N H_{3}\right)}=R T\left(10^{n_{1}-\frac{n_{2}}{T}}\right) \frac{\left[N H_{4}^{+}\right]}{H^{+}}$ 


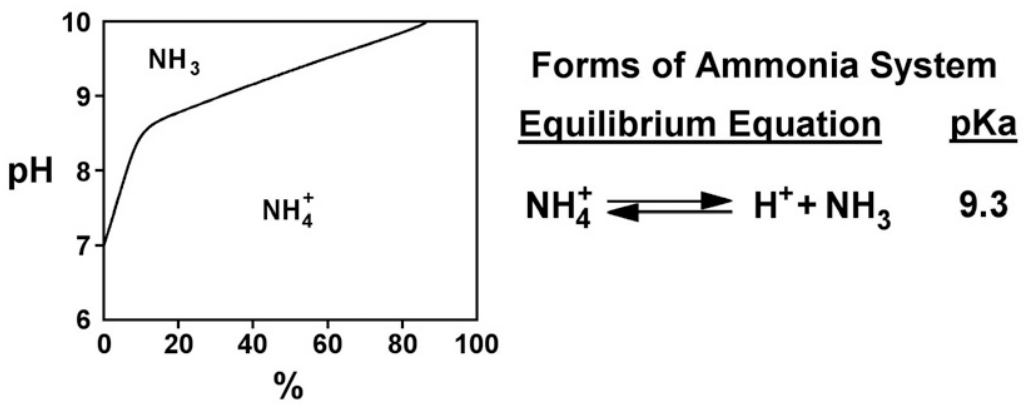

Fig. 15-2. Equilibrium relationship for ammoniacal $\mathrm{N}$ and resultant amount of $\mathrm{NH}_{3}$ and $\mathrm{NH}_{4}^{+}$as affected by $\mathrm{pH}$ of a dilute solution (after Koelliker \& Kissel, 1988).

where $R$ is the gas constant and $n_{1}$ and $n_{2}$ are derived constants (Denmead et al., 1982; Zhang et al., 1994; Harper et al., 2004a). The equilibrium equation for this reaction is shown in Fig. 15-2, along with the percentage of ammoniacal $\mathrm{N}$ ([AN]) that exists as $\mathrm{NH}_{4}^{+}$and $\mathrm{NH}_{3}$ for a dilute solution.

The physical effect is the ability of the wind turbulence to remove $\mathrm{NH}_{3}$ from the water-surface-atmospheric-boundary layer. For a soluble gas, such as $\mathrm{NH}_{3}$, the rate-limiting boundary layer is the diffusive air boundary layer. Removal of $\mathrm{NH}_{3}$ from this boundary layer is a function of the atmospheric turbulence (windspeed) and atmospheric stability [measured by Richardson's Number (Richardson, 1929)]. During seasonal studies when climatic conditions were reasonably constant, turbulence was found to account for as much as $75 \%$ of the variability in emissions over a swine lagoon (Harper \& Sharpe, 1998, unpublished data). An example of the interrelationship of windspeed and animal waste lagoon temperature with $\mathrm{NH}_{3}$ emissions is shown in Fig. 15-3. Variability in emissions among sources may be affected by the $\mathrm{pH}$ of the medium. As gaseous $\mathrm{NH}_{3}$ escapes from the medium solution, $\mathrm{NH}_{4}{ }^{+}$in the solution dissociates to $\mathrm{NH}_{3}$ to maintain the partial pressure of gaseous $\mathrm{NH}_{3}$ in the solution. Interestingly, as $\mathrm{NH}_{3}$ is lost by volatilization, $\mathrm{NH}_{4}^{+}$ions dissociate to $\mathrm{NH}_{3}$ and $\mathrm{H}^{+}$to maintain equilibrium in the solution (Koelliker \& Kissel, 1988). The net result is that volatilization tends to decrease $\mathrm{pH}$ and reduce the volatilization rate. A number of emissions models have been developed, basing the inputs on these measured components (Denmead et al., 1982; Zhang et al, 1994; Harper et al., 2000b, 2001, 2004a,b; DeVisscher et al., 2002;). Characterization of the turbulent component is the most difficult of these parameters to determine.

Conclusive studies on $\mathrm{NH}_{3}$ emissions from crops and animal production systems depend on reliable experimental and analytical techniques. The purpose of this chapter is to discuss field and analytical methods for measurement of $\mathrm{NH}_{3}$ losses. Methods employed most frequently to measure gaseous loss include: enclosure methods, in which the flux density of the gas at the surface is calculated from changes in gas concentration in an enclosure placed over the surface; noninterference micrometeorological techniques, in which the vertical or horizontal flux density of the gas is measured in the free air above the soil, plant, or water surface; and release of known tracer gases for ratioing the known and unknown emissions. 


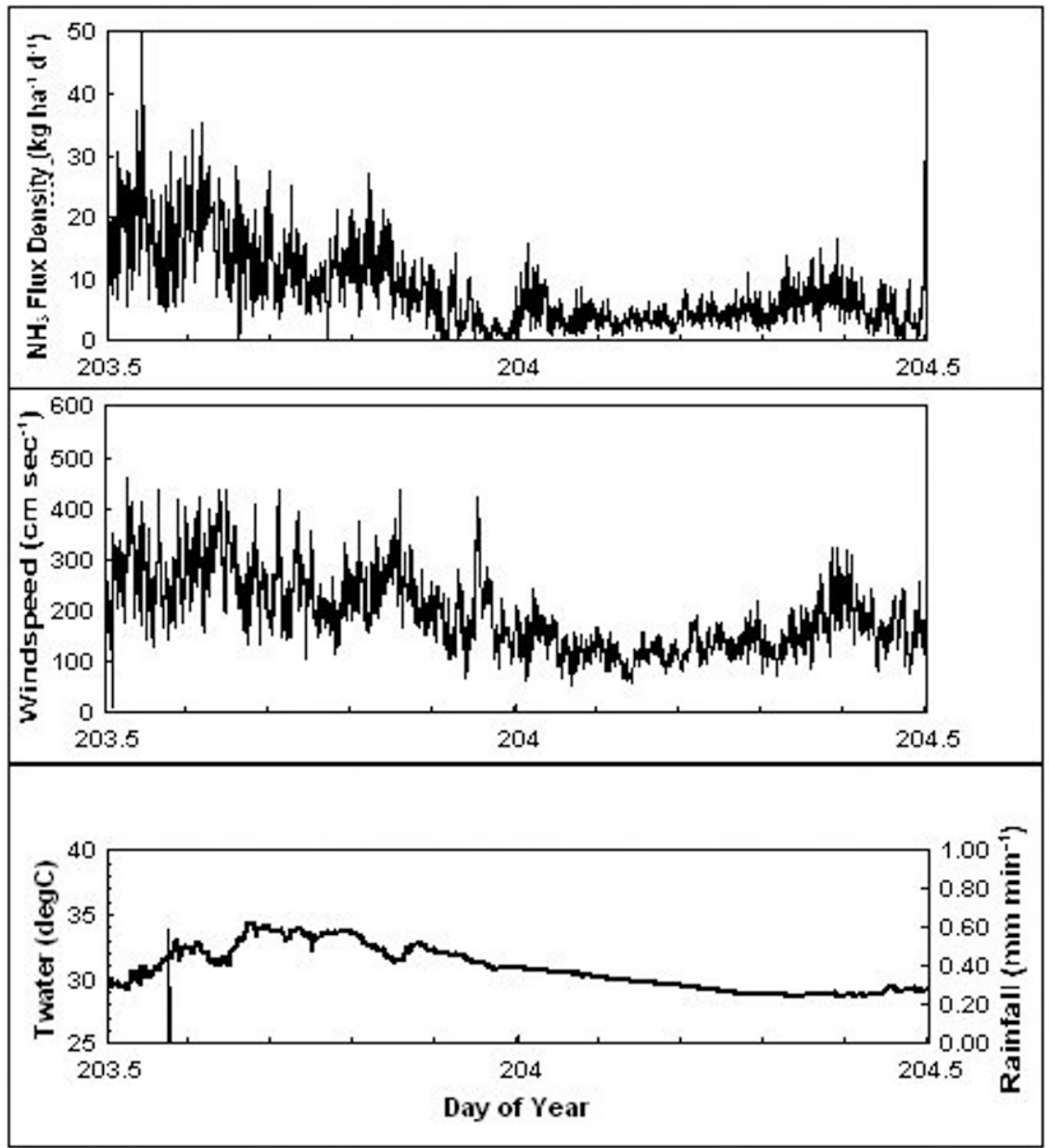

Fig. 15-3. Ammonia flux density variation compared with windspeed and lagoon water temperature over a swine lagoon (after Harper et al., 2001, 2004a).

\section{METHODS FOR MEASURING AMMONIA CONCENTRATION}

Historically, there has been a lack of reliable, fast-responding, and sensitive sensors for the measurement of $\mathrm{NH}_{3}$. There are several sensors becoming available and this review will not try to characterize available sensors because technologies are rapidly changing. There are, however, several classes of sensors for $\mathrm{NH}_{3}$ measurement.

\section{Gas-Washing}

This technique has been used as a standard for many years. Much of the early work on atmospheric transport was accomplished, by necessity, using this 
technique. The technique employs absorption of the atmospheric gaseous $\mathrm{NH}_{3}$ into an acid, such as sulfuric or phosphoric, where the air-flow rate through the acid and the length of time are known or measured. Both $\mathrm{NH}_{3}$ and volatile amines are "scrubbed" from the air sample but the total mass of volatile amines is normally quite small (Hutchinson et al., 1982). The $\mathrm{NH}_{3}$ average concentration is then calculated across the sample period from the solution $\mathrm{NH}_{4}{ }^{+}$concentration and the known flow rate. If the air is dusty or hazy, the incoming air sample should be filtered to avoid particulate contamination. With considerable sampling and chemical analysis care, during a period of 2 to $4 \mathrm{~h}$ a sensitivity of 0.5 to $1.0 \mu \mathrm{g} \mathrm{m}^{3}$ can be obtained (Weier et al., 1980). In situations with considerable dust, the air should be filtered to remove aerosol dust particles that may contain $\mathrm{NH}_{4}^{+}$. Additionally, gaseous amines will be absorbed but even in areas of high $\mathrm{NH}_{3}$ emissions the levels of amines will be rather small (Hutchinson et al., 1982). With background atmospheric concentrations ranging from 5 to $15 \mu \mathrm{g} \mathrm{m}^{3}$, this technique has been used extensively and continues to be used where fastsampling is not necessary and high-sensitivity is required. The technique is, however, very labor intensive and prone to sample-contamination. Consequently considerable quality assurance and control is required.

\section{Annular Denuders}

The principle of this technique is to pull air through glass tubes coated with either basic solution (such as sodium carbonate) for collection of acid gases or an acid solution (such as citric acid) to absorb basic gases. The denuder is a high surface area glass collection device designed to exclude particles from the collection surface allowing it to separate the vapor phase $\left(\mathrm{NH}_{3}\right)$ and particulate phase $\left(\mathrm{NH}_{4}\right)$ in ammoniacal air samples. In air, molecules diffuse more quickly than particles and gas-phase $\mathrm{NH}_{3}$ diffuses from the laminar flow to the coated wall while particles pass through the tube. Because of the much higher diffusivity of gases as they pass through the denuder, they have a higher probability of being collected by the coating, whereas the fine particles have a lower probability of collection, thus residence time in the denuder tube should be as short as possible (approximately a few seconds) to avoid the interference of $\mathrm{NH}_{3}$ evaporated from particles and gas-particle and particle-particle reactions. There are problems that must be addressed in these systems (McColloch \& Shendrikar, 2000) as comparisons to other measurement methods have shown that citric acid denuders consistently collect approximately $80 \%$ of the $\mathrm{NH}_{3}$ measured by a chemiluminescence analyzer. The relatively low precision found by McColloch and Shendrikar may suggest a random fluctuation in the dissociation of the citric acid/ $\mathrm{NH}_{3}$ complex, perhaps due to environmental variables. The use of phosphoric acid for coating may reduce this problem (Perrino \& Gherardi, 1999). If desired, the particles also can be collected by placing a filter pack at the end of the denuder. McCulloch et al. (1998) described a situation where hydrogen chloride, nitrous acid, nitric acid, sulfur dioxide, $\mathrm{NH}_{3}$, and fine aerosols of chloride, nitrate, sulfate, and $\mathrm{NH}_{4}$ particle measurement were made at each sampling using a series of two sets of denuders with filters appropriately placed between the denuders. The tubes may be configured as a single tube (Zhu et al., 2000), as concentric tubes (McCulloch et al., 1998), or a series of tubes, and air going through the tubes must be estab- 
lished as laminar flow. When using a denuder system to trap acid or basic gases, it is important to know when the denuder tube begins to lose its sorption efficiency (breakthrough) after a large volume of air has been sampled. Residence time of the air in tubing also should be known. Passive denuder samplers will collect both $\mathrm{NH}_{3}$ and $\mathrm{NH}_{4}$ at times of very low natural windspeeds; however, laminar flow rates may not be developed by low natural windspeeds. Another potential problem is the deposition of particles by gravitation on the tube wall at low windspeeds. This problem may be minimized by placing the tubes vertically; however, this configuration cannot be used for passive samplers (Schjorring et al., 1992) and "shuttles" (Denmead, 1983). It should be acknowledged that passive denuder samplers contain large approximation and empiricism (Sutton et al., 2000) but the technique has generated interest since it provides a much cheaper means of estimating long-term fluxes than the classical approaches.

Another type of denuder system is the continuous annular denuder systems such as the AMANDA (ammonia measurement by annular denuder sampling with on-line analysis; Wyers et al., 1993), batch rotating wet denuders (Keuken et al., 1988), and WEDD (wet effluent diffusion denuders; Neftel et al., 1998). These systems incorporate on-line chemical analysis and logging of the sampled $\mathrm{NH}_{3}$ and have been used successfully with both flux-gradient and relaxed eddy accumulation techniques (Sutton et al., 1997, 2000, 2001).

\section{Spectrometers}

There are several types of instrumentation that fall generally into this class. Closed-path spectrometers include chemiluminescence (McCulloch et al., 2001) and closed-path tunable diode laser spectrometers (Diaz et al., 1996; Warland et al., 2001). These instruments can be quite sensitive with proper sample handling and sequencing procedures. Open-path tunable diode laser spectrometers (Bauer et al., 1999) and open-path Fourier transform infrared spectrometers (OP-FTIR) provide a technique not requiring the gas sample to be transported to the laser source/detector site (Todd et al., 2001).

Chemiluminescence detectors use quantitative measurements of the optical emission from energized chemical species to determine analyte concentration and can take place in either the solution or gas phase. Tunable diode lasers can be adjusted to specific wavelengths to take advantage of gases that absorb light in a unique absorption signature or spectrum made up of a large number of individual absorption lines. Tunable diode lasers can be tuned to select a single absorption line of a target gas that does not overlap with absorption lines from any other gases, giving a capability of being very selective and not suffering interference from other gases. Open-path Fourier transform infrared spectrometers pass a single beam of light through the atmosphere that develops an absorbance spectrum. This absorbance spectrum is analyzed using a Classical Least Squares fitting program and calibrated reference spectra, since each spectrum exhibits a distinct pattern that varies predictably in relative intensity, line width, and line position. This capability allows for simultaneous measurement of a number of different interested gas species; however, uncertainty in results caused by spectral overlap has been a matter of concern. Similarly, any open- 
path (and closed-path where the sample is not dried) system may have concentration effects due to the presence of water vapor when the gas is in high concentrations. In the case of $\mathrm{NH}_{3}$, background concentrations need not be corrected since the ambient concentrations are quite small and the error is negligible (Denmead, 1983). This is fortunate since it is difficult to dry air without removing the $\mathrm{NH}_{3}$ as well. Further information on the use of spectrometers may be found in Wagner-Riddle et al. (2005, this volume).

\section{FLUX MEASUREMENTS}

In general, there are two types of measurements, those which interfere with the transport processes and those that are designed to minimize the interference of transport processes. These techniques fall into three classes of measurements that have generally been used-enclosure, micrometeorological, and tracer techniques.

\section{Enclosure Methods}

Noninterfering techniques are preferred for measuring $\mathrm{NH}_{3}$ gas fluxes because they do not disturb the sample area or its microclimate; however, enclosure or chamber methods are often used because they are simple, suitable for pot experiments and for small field plots, and may have a lower sensitivity requirement for measuring gas concentrations. They can enclose one or more plants and can allow separation of growth medium and plant, making it theoretically possible to determine the amount of $\mathrm{NH}_{3}$ (or other gases) that have been emitted directly and exclusively from the aboveground parts of plants. The air can be passed over a condenser and returned to the leaf. Reduced and oxidized compounds can be separated; however, $\mathrm{N}_{2} \mathrm{O}, \mathrm{NO}$, and $\mathrm{N}_{2}$ are not detected in this process since they are not very soluble. Researchers using this technique report higher losses from plant systems than that of other methods (Holtan-Hartwig \& Bockman, 1994) possibly due to the condensation of $\mathrm{CO}_{2}$ and $\mathrm{NH}_{3}$, leading to enhanced photorespiration, larger stomatal aperture, and an enhanced difference in partial pressure of $\mathrm{NH}_{3}$ from inside to outside of the leaf. Although some chambers have no circulation of air (Recous et al., 1988), $\mathrm{NH}_{3}$ volatilization rates will be sensitive to air circulation speed. Marshall and Debell (1980) compared sealed enclosures with and without circulation and found $31 \%$ greater $\mathrm{NH}_{3}$ loss from the enclosures with circulation. Also, it is very difficult to maintain gas concentrations at about ambient concentrations in the enclosure and to avoid pressure changes. In some experiments, air supplied to the chamber is scrubbed free of $\mathrm{NH}_{3}$ (Morgan \& Parton, 1989; Aneja et al., 1999), which may give more $\mathrm{NH}_{3}$ volatilization than under natural conditions, particularly if there are plants in the measurement system. Parton et al. (1988) obtained comparable results in a growth chamber simulating specific conditions in the field and obtained similar results by allowing long periods of equilibration before measurement began. Large errors have been found (Hoff et al., 1981) using enclosures and field losses estimated by this technique must be regarded as questionable, since the enclosure 
cannot closely duplicate soil, water-surface, and environmental aspects (McInnes et al., 1986).

An enclosure system developed by Kissel et al. (1977) was designed to minimize alteration of soil and environmental factors by removing the enclosure covers except for only short periods during measurement. Although removing the cover allowed normal environmental conditions to exist during the remainder of the time, Hargrove et al. (1987) expressed concern about extrapolating losses measured with the enclosure technique to field losses. They found that measurements inside the chambers indicated that windspeed at $1 \mathrm{~cm}$ from the soil surface were not representative of windspeeds in the field a significant percentage of the time. These differences were of particular concern when mulch or other roughness elements were used. This type of system, however, provides a useful means by which relative differences between treatments can be tested.

In further attempts to minimize differences between enclosures and the field, Vallis et al. (1982) and Lockyer (1984) developed "wind tunnel" enclosures whereby emphasis was placed on the requirement that the natural conditions of the plant community measured would be influenced as little as possible. The systems were designed so that airflow through the tunnel enclosure could be controlled within the range normally encountered in the field. This type of system requires treatments with $\mathrm{N}$ above background or the surrounding area since the gas concentrations between entrance and exit or between treatment and control enclosures are measured. Care must be taken in the design of these enclosures to avoid countergradient flux from the tunnel opening (Vallis \& Harper, 1982, unpublished data) and condensation on the inner surfaces (Vallis et al., 1982; Lockyer, 1984). Little effect was found on plant, air, or soil temperature and soil water content when air velocity through the tunnel was matched to the ambient windspeed (Vallis et al., 1982; Ryden \& Lockyer, 1985). Another consideration with the wind tunnel enclosure is that of rainfall, which can reduce $\mathrm{NH}_{3}$ loss (Fox et al., 1996). Relocating wind tunnels after rainfall events enables the effects of rainfall to be included (Ryden \& Lockyer, 1985); however, tunnel relocation may be impractical where the objective is comparative data (Thompson \& Meisinger, 2001, unpublished data) between treatments. When wind tunnels are used at fixed windspeeds, and there is an appreciable difference between the tunnel windspeed and ambient windspeed, there is probably an error in the estimate of loss rates (Thompson \& Meisinger, 2001, unpublished data). Additionally, the presence of canopies may restrict surface gas exchange by reducing the development of turbulent eddies that transport air from the soil in open field conditions (Harper, 1988). Nevertheless, wind tunnel chamber systems qualitatively track $\mathrm{NH}_{3}$ loss and enable replicated comparisons of different treatments.

There are a number of other problems associated with using enclosures to measure $\mathrm{NH}_{3}$ flux. These problems are associated with the chemistry of the gas and the strong effect that environmental conditions have on the volatilization processes (Denmead, 1983). Factors such as radiation, energy balance, evaporation rate, temperature, windspeed, and dew formation all have important influences and the effects of these factors are difficult to mimic in enclosures. Ammonia is highly reactive and readily soluble in water and thus is likely to adsorb and desorb from the measurement enclosure and tubing walls. [Consider- 
able effort has been expended to determine the best materials to be used in $\mathrm{NH}_{3}$ measurement systems. Experience (Thurtell \& Harper, 2000, unpublished data) has suggested the following materials from better to worse: clear, low-density polyethylene $>$ Teflon $>$ glass $>$ stainless steel $>$ nylon. Previous studies (Hutchinson, 1987, unpublished data) used oxidized nickel tubing to minimize $\mathrm{NH}_{3}$ absorption.]

Generally, the surface area enclosed by chambers is relatively small, often $<1 \mathrm{~m}^{2}$, whereas the point-to-point variability of $\mathrm{NH}_{3}$ and other gas emissions from soils, plants, and water systems may be quite large (Denmead \& Raupach, 1993). Soil emission rates may vary 2 to 10 times within a few meters (e.g., Matthias et al., 1980; Galbally et al., 1985) creating highly variable results from chamber measurements. For example, Folorunso and Rolston (1984) found coefficients of variation of 282 and $379 \%$ in chamber measurements of $\mathrm{N}_{2} \mathrm{O}$ emissions and calculated that as many as 350 measurements would be necessary to estimate the true mean flux within $\pm 10 \%$ on a $3 \times 36$ m experimental plot. Plant systems may be even more variable although variations in water systems may be somewhat less variable (Harper \& Sharpe, 2002, unpublished data). To circumvent the large spatial variability of chambers, multi-chamber and large-chamber systems have been developed. A system of 16 chambers was constructed (Schultz \& Seiler, 1989) where each enclosed an area of $1 \mathrm{~m}^{2}$ with lids closing periodically under computer control. Methane emission rates were determined eight times per day and the system remained in place for the growing season. Very large chambers have been constructed of light-weight plastic. One of these systems (Galle et al., 1994) enclosed an area of $64 \mathrm{~m}^{2}$ and used a long-path Fourier Transform Infrared (FTIR) Spectrometer to measure changes in the concentrations of $\mathrm{CH}_{4}$ and $\mathrm{N}_{2} \mathrm{O}$. Another system (M. Poach and P. Hunt, 2001, personal correspondence) was used to cover the width of a constructed wetland for processing animal wastes. The chamber fit the cross-section of the constructed wetland and was tall enough to include the wetland vegetation. This system was developed for use in areas where turbulence was too erratic for microclimate measurements. Gas washing techniques were used for $\mathrm{NH}_{3}$ concentration determination.

Because of the unique properties of $\mathrm{NH}_{3}$, there is a pressing need for nondisturbing measurements of this trace gas flux that integrate across larger areas and longer time scales. Micrometerorological techniques offer more promise in these respects.

\section{Micrometeorological Methods}

Micrometeorological methods are noninterference methods and are preferred in principle over interference methods such as chambers (Denmead, 1983; Ferguson et al., 1988; Harper, 1988) because (i) they do not disturb the soil, plant, water system, or environmental processes that influence $\mathrm{NH}_{3}$ exchange; (ii) they allow continuous measurement, facilitating the investigation of environmental effects on the production and transport of emissions; and (iii) they provide average emissions across an area, minimizing the sampling problem of point-topoint variation found using enclosure techniques; however, their successful application requires relatively large experimental areas (causing problems of practical 
replication) and emissions are often small, requiring very sensitive equipment and careful attention to measurement protocol. Micrometeorological techniques assume sources and sinks of energy and mass are evenly distributed and may require a considerable amount of data processing before data analysis. Several types of micrometeorological methods have been applied to $\mathrm{NH}_{3}$ measurements. Meyers and Baldocchi (2005, this volume) review a broad range of micrometeorological methods for trace gases, many of which have been used for $\mathrm{NH}_{3}$. They include:

1. Eddy Covariance. The basic concept of gas transport is that the mass of gases is transported by the eddying motion of the atmosphere and the instantaneous vertical flux density of a gas is the product of the vertical windspeed, $\omega$, and its density, $\rho_{\mathrm{g}}$, described by the equation,

$$
F=\overline{\omega \rho_{g}}+\bar{\omega}^{\prime} \bar{\rho}_{g}^{\prime}
$$

where bars denote average across a period and primes, the fluctuations about the means (Denmead, 1983). Meyers and Baldocchi (2005, this volume) describe the assumptions underlying eddy covariance.

Fast response sensors are required (and a number of sensors for $\mathrm{NH}_{3}$ have been developed) but fluxes will be underestimated if the sensor responds too slowly, so to keep the necessary correction small (Hicks, 1972), sensor deployment should be no less than two response lengths above the measurement surface [see LeClerc and Thurtell (1990) for a discussion of fetch/height ratios]. Consequently, a large fetch is needed for the assumption of no flux divergence to be met in practice. Additionally, simultaneous measurement of heat and water vapor for correctional measurements is required. For most gases, preconditioning of the air streams to remove $\mathrm{H}_{2} \mathrm{O}$ vapor precludes the need for water vapor correction; however, for $\mathrm{NH}_{3}$, drying is not yet practical. In most situations, the $\mathrm{NH}_{3}$ concentrations are small enough that errors associated with corrections for density fluctuations are small and corrections are not necessary.

2. Gradient and Aerodynamic Techniques. These techniques are based on an analogy between turbulent transport and molecular diffusion, assuming both processes transport a gas along its mean concentration gradient. Application of these methods is limited to measurements above crops or other systems where there is adequate profile development of windspeed, temperature, and gas concentrations. An additional assumption is that horizontal concentration gradients are negligible in relation to vertical gradients. If these requirements are met, the vertical flux density of the gas in question will be constant with height in the air layers close to the measurement surface and a one-dimensional (vertical) analysis can be made (Denmead \& Raupach, 1993). This method has been widely used and measurement of gas transport between soils, plants, water systems, and the atmosphere has been reported by a number of researchers [Harper et al., 1973, 1976, 1983, 1987, 1996, 2000a, 2000b, 2001, 2004a; 
Harper \& Sharpe, 1995, 1998; Sharpe \& Harper, 1997, 1999;

Lemon \& Van Houtte, 1980; Hutchinson et al., 1982; Denmead et al., 1974, 1976; Freney et al., 1981; Bussink et al., 1996; Sutton et al., 1997, 2000].

The usual form of the gradient diffusion relationship is

$F_{F G}=-K_{g}\left(\partial \rho_{g} / \partial z\right)$

where $\rho_{\mathrm{g}}$ is the density of the gas in question with respect to height $z$ and $K_{\mathrm{g}}$ is the eddy diffusivity or transport coefficient of the gas. Prueger and Kustas (2005, this volume) discuss the method in detail, including methods to estimate $K_{\mathrm{g}}$ from wind profile data and approaches to correct for atmospheric stability.

\section{Energy Balance Method}

The energy balance method is an alternative approach to determining the flux-gradient eddy diffusivity. In this technique, all radiative and turbulent energy components are balanced as in Eq. [5],

$$
R_{n}+G+\int_{z_{1}}^{z_{2}} \beta(z) d z+\ell k_{E_{(z)}} \frac{\partial e}{\partial z}+c_{p} \rho k_{H_{(z)}} \frac{\partial T}{\partial z}+\lambda k_{C_{(z)}} \frac{\partial c}{\partial z}+M=0
$$

where $R_{\mathrm{n}}$ is net radiation, $G$ soil energy flux, $\ell$ latent heat of evaporation, $e$ absolute humidity of air, $c$ carbon dioxide concentration, $c_{p}$ the heat capacity of air, the plant energy flux (heat), $\lambda$ the energy conversion for fixation of $\mathrm{CO}_{2}$, and $M$ a residual term associated with energy storage. Equality of the diffusivity coefficients is assumed (Lemon, 1967; Denmead \& Raupach, 1993) and the equation is rearranged to solve for the transport coefficient. The Bowen ratio method for measuring evaporation is an extension of the energy balance technique and is described by Fritschen and Fritschen (2005, this volume). The technique assumes equality of transport coefficients for heat, water vapor, and $\mathrm{NH}_{3}$, so that measurements of each at two heights is sufficient to determine the fluxes of all three. A disadvantage of the energy balance method is that in early morning, late evening, and nighttime, $R_{\mathrm{n}}$ and $G$ become small or approach the same value, which means that since the accuracy of the flux density estimate is proportional to the accuracy of the $R_{\mathrm{n}}$ and $G$ measurements, the error may become large. Further, as these values approach zero, the error becomes infinite. Also at night, condensation on the instrumentation can cause erroneous measurements. Since many of the measurements are common to both techniques, both the momentum and energy balance methods should be used in conjunction giving a comparison in diffusivity coefficients during periods when the energy balance technique may be used.

Energy and mass do not transport identically under all conditions and the use of energy to determine mass transport coefficients will require corrections to the transport coefficient. Recent studies suggest that while the eddy diffusivity for momentum $\left(K_{\mathrm{m}}\right)$ in the atmosphere is reasonably well known, the eddy diffusivity for mass $\left(K_{\mathrm{c}}\right)$ is more uncertain. This uncertainty can be conveniently 
expressed as uncertainty in the turbulent Schmidt number $(S c)$ [Flesch et al., 2002]:

$$
S c=\frac{K_{m}}{K_{c}} .
$$

Most flux-gradient (classical) relationships assume that $S c$ value is 1.0; however, some authors have observed this possible underestimation of flux-gradient emissions and have scaled their estimates of emissions by 30\% (Simpson et al., 1995; Wagner-Riddle et al., 1996; Flesch et al., 2002) who justified this adjustment as giving better agreement with energy balance observations and the derivation of the energy balance eddy diffusivity, $K_{\mathrm{eb}}$.

\section{MASS BALANCE METHODS}

\section{Integrated Horizontal Flux Method}

The eddy covariance and gradient methods require extensive and uniform surface areas for sufficient profile development. One mass balance technique, commonly called the integrated horizontal flux (IHF) method, overcomes this limitation. Flux densities are determined from the differences in the quantity of gas carried by the wind across the upwind and downwind boundaries of an experimental area (Denmead et al., 1974; Denmead, 1983). Instrumentation is relatively simple, requiring only windspeed and gas concentration profiles and wind direction. The concept is relatively simple and physically correct with no requirement for stability corrections. Flux density is given by

$$
F_{I H F}=\frac{1}{x} \int_{z_{0}}^{z_{p}} \overline{\left(u \rho_{g}+u^{\prime} \rho_{g}^{\prime}\right) d z}
$$

where $x$ is the fetch (which must be known precisely) between the measurement boundaries, $z$ is the height with $z_{0}$ denoting the height at which the windspeed goes to zero, $z_{\mathrm{p}}$ the height of the limit of the modified profile, and $\overline{u \rho_{\mathrm{g}}}$ (where $\overline{\rho_{\mathrm{g}}}$ denotes gas density in excess of background) the time-average horizontal flux density at any particular level in the vertical plane. All planes are integrated (summed) vertically to get the total flux density. The $\overline{u \rho_{\mathrm{g}}}$ is the flux due to horizontal convection while the $u^{\prime} \rho_{g}^{\prime}$ is the flux due to horizontal diffusion (countergradient flux that occurs in the direction opposite to that of the wind). Raupach and Legg (1984) suggest that the diffusion term is usually $<10 \%$ and can be omitted. Footprint analysis (Wilson et al., 1982; LeClerc \& Thurtell, 1990) has shown that more than $90 \%$ of the emitted gas will be contained within a gas cloud that will extend vertically to a height, $z$, which is about $1 / 10$ of the fetch (upwind turbulent characteristics). Practical experience (Denmead, 1983) suggested that for small fetches, a good working approximation is that $z_{\mathrm{p}} \cong 0.1 x$. Vertical measurement heights must take into account the influence of stability on the shape of profiles of the trace gas (Fig. 15-4). Five measurement levels should be used for a 


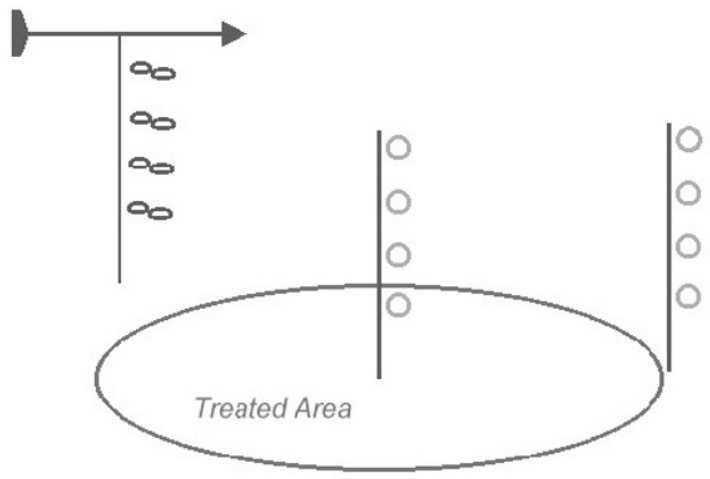

Fig 15-4. Conceptual schematic of the IHF technique.

well-defined profile situation in a short crop but more measurements may be needed if irregular profiles are obtained.

A simplification (experimentally) of the IHF method was proposed by Philip (1959) and Wilson et al. (1982), based on the assumption of a particular height within the modified layer where the normalized horizontal flux (i.e., $\overline{u \rho_{\mathrm{g}}} / F$ ) has about the same value in all stability conditions. If the appropriate value of the normalized horizontal flux at that height is known, then measurements of $\bar{u}$ and $\overline{\rho_{\mathrm{g}}}$ only at that height are necessary to determine $F$. Denmead (1983) and McInnes et al. (1985, 1986) and Meissinger (2000, personal communication) discuss the method and indicate that the fluxes agreed well with the IHF method. The method by Philip showed less variation but slightly overestimated the IHF method, while the Wilson et al. method showed larger variation but slightly underestimated the IHF method. A further simplification was developed by Denmead (1983) and Leuning et al. (1985) using an isokinetic gas sampler with an air intake of area $(A)$ that trapped a mass of gas $(M g)$ during time $(t)$. The $M g / A t$ is then $\propto \overline{u \rho_{\mathrm{g}}}$, and a single determination $M g$ at the end of the study (perhaps lasting several days) will provide a measure of the total gas loss from the area.

\section{Micrometeorological Mass Difference Method}

Large test areas required for application of conventional micrometeorological approaches and spatial variability in horizontally spatial emissions rates present problems in many situations where measurements of trace gas exchange are required. Some examples include emissions of gases from small, treated plots or contaminated sites where lateral dimensions are 10 s rather than 100 s of meters and the source distribution is not uniform. In a landfill, Czepiel et al. (1996) reported a coefficient of variation of $326 \%$ for 139 point measurements of methane emissions. In this circumstance, the measurement problem becomes two- or three-dimensional and conventional micrometeorological methods are not appropriate. Similarly, gas may be produced from scattered point sources that 
may even vary temporally in location horizontally and vertically, such as grazing animals. Certainly, this measurement situation becomes a three dimensional problem. To resolve this problem, Harper et al. (1999) developed a micrometeorological mass difference method (MMD) that is an extension of the IHF method (Fig. 15-5).

When gas is released from the ground into the atmosphere, it is convected horizontally by the wind while diffusing laterally and vertically (Denmead et al., 1998a). In unstable conditions, the height of the gas cloud will be greater and in stable conditions, smaller. If the source is above the soil surface, such as from animals (Harper et al., 1999), the height above the soil surface must be accounted for in the vertical measurement heights. The effect of a canopy, if present, is negligible as long as there is no unmeasured horizontal flux divergence above the uppermost measurement height. The horizontal convective flux density at a point in the atmosphere is then given by the product of horizontal windspeed, $u$, and the gas density, $\rho_{\mathrm{g}}$. If emissions are within a defined space, the flux from the source can be calculated from the difference between the total gas fluxes across the upwind and downwind boundaries for the space. If the emissions are released within the confines of a square field of side $x$, such as in Fig. 15-6, then its mean emission rate, $\bar{F}$, can be given by

$$
\bar{F}_{M M D}=\int_{0}^{z} \int_{0}^{x}\left[\bar{U}_{z}\left(\bar{\rho}_{g_{4, z}}-\bar{\rho}_{g_{2, z}}\right)+\bar{V}_{z}\left(\bar{\rho}_{g_{3, z}}-\bar{\rho}_{g_{1, z}}\right)\right] d x d z
$$

where horizontal distance is $x$ with boundary numbers $n$ and $\bar{U}$ and $\bar{V}$ are the wind vectors perpendicular to each other. Time averages are denoted by an overbar. By

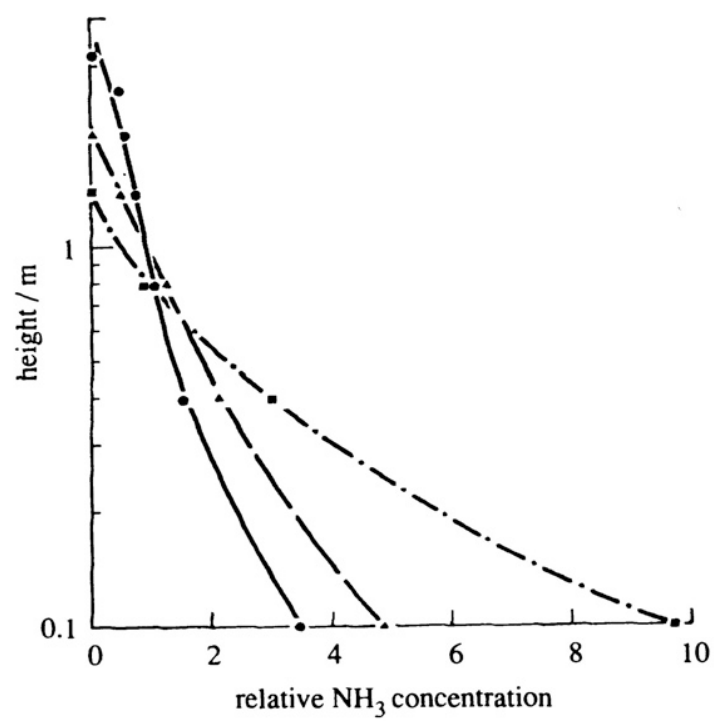

Fig 15-5. Influence of stability on shape of profiles of atmospheric ammonia across a urea-treated plot. Unstable, solid line; neutral, dashed line; stable, dash-dot line (after Denmead, 1983). 
fixing the horizontal distance as in Fig. 15-6, the relationship in Eq. [7] reduces to

$$
\bar{F}_{M M D}=\int_{0}^{z}\left[\overline{U_{z}}\left(\left\langle\bar{\rho}_{g_{4 . z}}\right\rangle-\left\langle\bar{\rho}_{g_{2 . z}}\right\rangle\right)+\bar{V}_{z}\left(\left\langle\bar{\rho}_{g_{3 . z}}\right\rangle-\left\langle\bar{\rho}_{g_{1 . z}}\right\rangle\right)\right] d z
$$

where the angular brackets denote spatial averages. Equation [8] can be evaluated numerically using the trapezoidal rule.

The net horizontal flux density of gas, $q$, is the time mean of the product of the instantaneous windspeed and gas density, $q=\overline{u \rho_{\mathrm{g}}}$. If $u$ and $\rho_{\mathrm{g}}$ are the sums of the time means and deviations from those means are denoted by primes, then $q=\overline{u \rho_{g}}+\overline{u^{\prime} \rho_{g}^{\prime}}$. The first term on the right side of the preceding equation is the convective flux. The last term represents the turbulent, diffusive flux in the upwind direction along the concentration gradient. Field tests by Leuning et al. (1985) suggests that the apparent horizontal flux overestimates the true flux by about $15 \%$. With measurements in fetches using the IHF technique, where emissions are uniform and emissions are from the soil surface, a good working approximation for $z=0.1 x$; however, when emissions are not at the soil surface (such as from animal breaths), $z$ must be increased to account for this height (Harper et al., 1999).

This technique has been used for measuring enteric $\mathrm{CH}_{4}$ emissions from grazing and feedlot animals (Harper et al., 1999; Denmead et al., 1998b; Harper et al., 2001), $\mathrm{N}_{2} \mathrm{O}$ emissions from grazed pastures (Leuning et al., 1998; Denmead et al., 2000b, 2000c), and $\mathrm{CH}_{4}$ and $\mathrm{N}_{2} \mathrm{O}$ from landfills (Denmead et al., 1998a). This technique may not be used for reactive gases such as $\mathrm{NH}_{3}$ emissions because of the problem of absorption-desorption of the gases on the sampling tubing; however, with the advent of multiple-sensor, open-path laser spectrome-

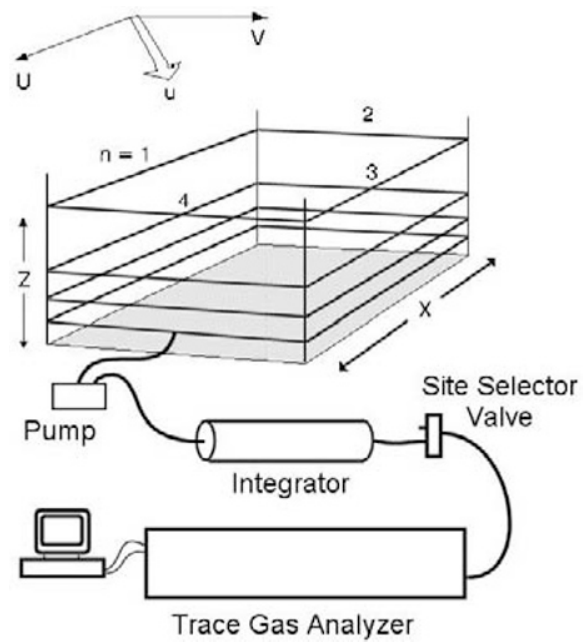

Fig. 15-6. Measurement scheme for the micrometeorological mass difference technique (after Harper et al., 1999). 


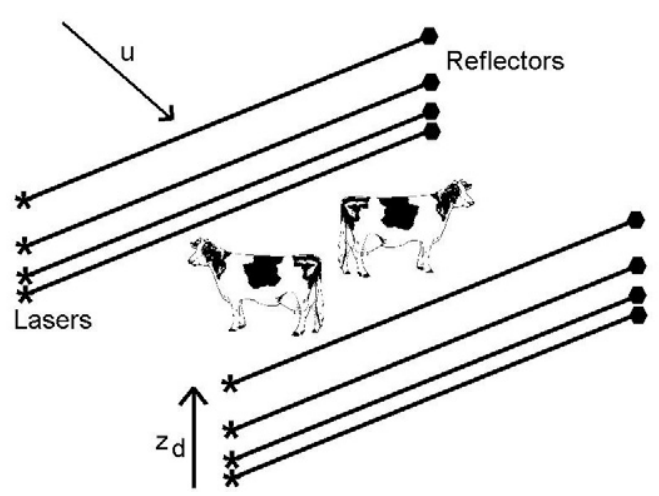

Fig. 15-7. Measurement setup for a noninterference modified mass balance technique to measure trace-gas emissions from crops and animal systems (after Harper, 2001, unpublished data).

ters for $\mathrm{NH}_{3}$, this technique may become useful to measure source emissions that are horizontally, vertically, and temporally variable. Harper (2001, unpublished data) developed a modified mass balance technique of the same principle as the MMD technique to be used with vertically-arrayed open-path lasers (Fig. 15-7). This technique, currently under development, would be useful for variable sources (spatially and vertically) and would have minimal interference and/or stress on crops or animals. Since only upwind and downwind measurements are made, this technique must be used in a general cross-wind direction. The first trials Denmead et al. (2003) of 23 release studies with an exclusion angle (the angle between the source and the ends of the laser line) of $10^{\circ}$, regression of recovered versus released gas emissions gave a mean recovery of $105 \%\left(r^{2}\right.$ of 0.91$)$ with a $4 \%$ standard error. Allowing for the 5\% overestimation of recovery, the system could detect a $9 \%$ change in emission rate with a probability of $5 \%$.

\section{Normalized Horizontal Flux Method}

A further extension to the IHF concept is that both theory and experiment indicate that (in certain situations), it is possible to infer the surface flux from measurements of the horizontal flux at just one height above the measurement plot center. Three requirements must be met, however, (i) although the treated plots may be relatively small, the treated area in which the plots are located must be large and uniform enough so that the wind profiles are equilibrium profiles, (ii) the treated area should have no vegetative cover (at least a very short cover) so that virtually all of the horizontal flux occurs in the unobstructed air layer above the surface, and (iii) the surface emission should be driven by processes in the soil and/or vegetation rather than by the atmospheric gas concentration (i.e., there should be a constant flux rather than a constant concentration boundary condition at the surface). The profile of horizontal flux density has theoretically predicable shape that is determined by surface roughness, plot geometry, and atmospheric stability (Philip, 1959; Mulhearn, 1977, Wilson et al., 1982). From analysis of the influence of stability on profile shape, Wilson et al. (1982) pre- 
dicted the existence of a particular height within the plot boundary layer at which the normalized horizontal flux, $\overline{u \rho_{\mathrm{g}}} / F$ has almost the same value in all stability situations. This height is denoted $z_{\text {inst }}$ and if the appropriate value of $\overline{u \rho_{\mathrm{g}}} / F$ at $z_{\text {inst }}$ is known, measurements of $\bar{u}$ and $\overline{\rho_{\mathrm{g}}}$ at only that height are sufficient to determine $F_{\mathrm{g}}$ (Wilson et al., 1982, 1983; Denmead, 1983). Freney et al. (1992) have used an extension of this concept with a passive sampler to measure the horizontal flux of $\mathrm{NH}_{3}$ at the $z_{\text {inst }}$. Denmead $(1983)$ and McInnes et al. $(1985,1986)$ and Meissinger (2000, personal communication) discuss the method and indicate that the fluxes agreed well with the IHF method. A further simplification was developed by Denmead (1983) and Leuning et al. (1985) using an isokinetic gas sampler with an air intake of area $(A)$ that trapped a mass of gas $(M g)$ during time $(t)$. The $M g / A t$ is then $\propto \overline{u \rho_{\mathrm{g}}}$, and a single determination of $M g$ at the end of the study (perhaps lasting several days) will provide a measure of the total gas loss from the area.

\section{LAGRANGIAN METHODS}

\section{Lagrangian Dispersion Analysis}

Flux-gradient techniques have been used extensively to describe $\mathrm{NH}_{3}$ transfer between the atmosphere and crop surfaces (Denmead, 1983; Harper, 1988), but theoretical difficulties limit the use of flux-gradient techniques within plant canopies, particularly where there are vertically distributed sources and sinks. The Lagrangian dispersion theory developed by Raupach (1989) enables a prediction of the gas concentration profile, which he designated as $C(z)$ from knowledge of the source strength, $S(z)$. The inverse Lagrangian method described by Raupach (1989) builds on that work to allow the inference of $S(z)$ from $C(z)$. Flesch and Wilson (2005, this volume), gives a complete discussion of the technique. This technique has been used (Raupach et al., 1992; Denmead et al., 2000a) to deduce source and sink strengths for $\mathrm{H}_{2} \mathrm{O}$ vapor, heat, and $\mathrm{CO}_{2}$ exchange in crop canopies, showing interesting emissions and adsorption/absorption sites. Harper et al. (2000a) extended the analysis to identify sources and sinks of $\mathrm{NH}_{3}$ in a canopy following sprinkler application of dairy effluent. The technique allowed an examination of the processes of loss within the canopy showing small but not insignificant $\mathrm{NH}_{3}$ losses from the soil, while showing unexpectedly large losses occurring from the foliage in the top half of the canopy.

Comparisons between Lagrangian and "conventional" micrometeorological methods have shown generally excellent agreement and comparable to the mutual agreement among the conventional methods of eddy covariance, energy balance, and momentum balance.

\section{Backward Lagrangian Stochastic Analysis}

The usual and most obvious meaning of a theory of atmospheric dispersion is that it defines a forward "source-receptor relationship" from a source field, and on the basis of some assumptions about the turbulent flow, it gives expression for 
a resultant mean concentration field (Wilson et al., 2001). An important point is that it is possible to exploit a given source-receptor relationship to infer flux density from a measured concentration-given some "supporting" information defining the flow. Flesch et al. (1995) introduced the "backward Lagrangian stochastic" (bLS) source-receptor method, applicable to a source of any geometry, and is described in detail elsewhere in this volume (Flesch and Wilson, 2005, this volume).

In this technique, one measures the gas concentration at a single point, $C_{\mathrm{p}}$, and the variables defining the state of the surface layer (At least minimally a single windspeed, $\mathrm{u}_{\mathrm{ref}}$, and wind direction is required. For improved accuracy, atmospheric stability, $L$, is needed.). The model is applied by generating an ensemble of $\mathrm{N}$ trajectories, such as $\mathrm{NH}_{3}$, from a point, $P$, backward in space and time (Fig. 15-8), and where any trajectory touches the ground, the point $(x, y, z)$ is recorded and the particle's touchdown position and vertical velocity, $F_{\text {bLS }}$, is inferred from those touchdowns as

$$
F_{b L S}=\frac{u_{r e f} C_{P}}{N} \sum\left(\frac{w}{U_{r e f}}\right)^{-1}
$$

where the summation runs over all touchdowns on the source (Wilson et al., 2001).

To illustrate the potential magnitude of errors, Wilson et al. (2001) added conservation equations for a tracer gas to a "local advection" model (Rao et al., 1974) to simulate emissions from a lagoon with a spatially uniform emission rate, $Q$. They generated spatial distributions of windspeed, temperature, and tracer concentration above and downwind of the lagoon. These simulated data provided the basis for a synthetic experiment where several micrometeorological estimates of the emission rate were compared with the prescribed $Q$. They compared these estimates of synthetic data and found that the fluxes in the synthetic data set estimated by the IHF compared well with the known $Q$ but not as well with flux-gradient estimates by the momentum balance method.

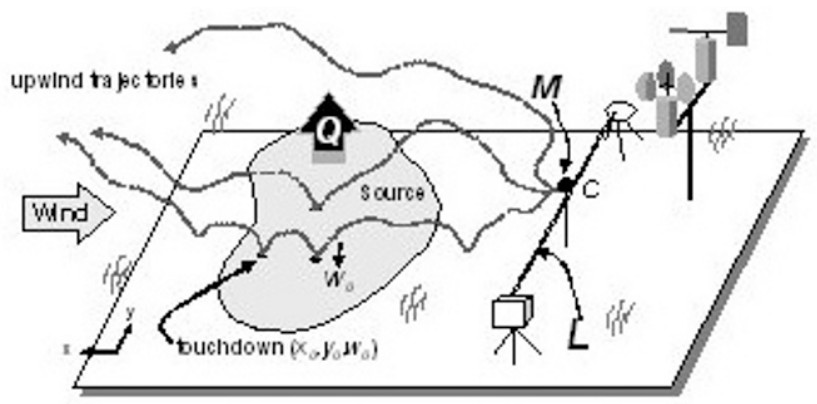

Fig. 15-8. Illustration of the bLS technique for estimating tracer emission rate $(Q)$. Average concentration $C$ is measured at point $M$ or line $L$ downwind of the source. The ratio $(C / Q)_{\text {sim }}$ is calculated from upwind trajectory "touchdowns" inside the source $\left(w_{0}\right.$ is the vertical velocity at touchdown; after Flesch et al., 2003). 
Further comparisons using $\mathrm{CH}_{4}$ and $\mathrm{NH}_{3}$ as tracer gases were made and the estimates of prediction in uniform flow across a field release surface area were quite good. Studies by Flesch et al. (2004) considered the bLS method as applied to an ideal case: estimating emissions from a synthetic source (a square grid of gas emissions of known rate) located in an open landscape where the MoninObukhov similarity theory (MOST) is likely to be upheld. They found the diagnosed emission rates $\left(Q_{\mathrm{bLS}}\right)$ were satisfactory when MOST gave a good description of the surface-layer, but poor during periods of extreme atmospheric stability and transition periods in stratification. With such periods eliminated, the average $Q_{\mathrm{bLS}}$ over-predicted the true $Q$ by only $2 \%$; however, individual 15-min predictions exhibited sizeable variability. In the best case where MOST gave a good description, the variability in $Q_{\mathrm{bLS}}$ was approximately $20 \%$ of $Q$.

\section{OTHER MICROMETEOROLOGICAL METHODS}

\section{Relaxed Eddy-Accumulation}

An alternative to enclosure and techniques based on atmospheric turbulence, the relaxed eddy-accumulation (REA) technique is a relatively new method for measuring trace gas fluxes. It involves the partitioning of the gases traveling vertically (up and down) into two separate reservoirs, based on whether a real-time wind-measuring system (normally sonic anemometer) that senses ascending or descending air movement. The separate samples can be absorbed into gas washing reservoirs that can later be analyzed, be sampled by continuous denuder technology (Businger \& Oncley, 1990), or be analyzed instantaneously by tunable diode laser spectroscopy (Diaz et al., 1996). Originally, Desjardins (1972) and Desjardins et al. (1984) developed the technique to sample the air at a rate proportional to the magnitude of the vertical wind velocity, $w$. Businger (1990) suggested a relaxation of this method in which the valves split the flow strictly on the basis of the sign of $w$ without the proportional sampling. The conceptual simplicity of this technique is appealing because the vertical flux estimate, $F$, for a trace gas is a simple function of the standard deviation of the vertical wind velocity, $\sigma_{\mathrm{w}}$, the difference of the mean concentrations between the ascending air $c^{+}$) and descending air $c^{-}$), and an empirical coefficient $A$,

$$
F_{R E A}=A \sigma_{w}\left(\overline{c^{+}}-\overline{c^{-}}\right)
$$

Field experiments have indicated that the REA works quite well as an alternative measurement technique for nonreactive gases such as $\mathrm{CO}_{2}$, volatile organic compounds, and pesticides (Majewski et al., 1993; Pattey et al., 1993; Zhu et al., 1999); however, because of the reactivity, stickiness, and ability to convert to $\mathrm{NH}_{4}{ }^{+}, \mathrm{NH}_{3}$ sampling using REA requires careful sample handling and/or measurement. The annular denuder system (ADS) is a suitable trap for this purpose (Zhu et al., 2000) to avoid the interference of $\mathrm{NH}_{4}{ }^{+}$in particulate phase with the collection of gas-phase $\mathrm{NH}_{3}$-if (i) there is need to separate the constituents and (ii) the $\mathrm{NH}_{4}^{+}$constituent is sufficiently high compared with $\mathrm{NH}_{3}$. 


\section{Gaussian Plume-Puff Dispersion Model}

Gaussian plume and puff models have become a standard for modeling atmospheric dispersion for two reasons: simplicity and flexibility. They are attractive because of the large degree of flexibility in handling arbitrary source characteristics (continuous line source, moving source, etc.), effluent characteristics (buoyancy, stack downwash, etc), and varying meteorological conditions. They are promoted as having a modeling range of 10 s of meters to 1000 s of kilometers.

Despite its apparent sophistication, the Gaussian framework is rather primitive. While the derivation of these models starts with the rigorous mass-conservation equation, often a host of unrealistic assumptions are then employed: homogeneous wind field (conditions of steady, uniform wind-flow, spatiallyindependent turbulence), a gradient-diffusion hypothesis of turbulent transport, and mass diffusivities independent of position (Arya, 1999). The result is a deceptively simple relationship for the concentration field downwind of an emission source. The key model parameters are the plume "sigmas," the standard deviation of plume-puff spread in each direction downwind of the source $\left(\sigma_{x}, \sigma_{y}\right.$, $\left.\sigma_{\mathrm{z}}\right)$. However, because the underlying Gaussian model assumptions are not generally realistic, these models are essentially empirical, and the sigma functions are determined by fitting experimental data. The Gaussian modeler must assume that the sigma functions derived from another particular experiment will be valid in their situation (McColloch, 1999); however, since the Gaussian framework does not describe the atmosphere, these sigma relationships are not universal. They vary with weather conditions, local terrain, source geometry, concentration observation locations, etc., and to be successfully employed, the Gaussian model requires the user to find an experimental value for the sigmas in a situation as close to theirs as possible. In many agricultural and environmental applications, accurate models of dispersion near the ground $(z<100 \mathrm{~m})$ and across short ranges $(x<1000 \mathrm{~m})$ are required. These conditions are where Gaussian models are most unreliable. Near the ground, the average wind and turbulence levels change dramatically with height, invalidating the foundation of Gaussian models (Flesch, 2001, personal communication). In these cases, Gaussian models should be used with a great deal of caution. Different experiments will yield different sigma relationships.

In a comparative study of several techniques in eastern North Carolina, Gaussian model results in summer (McColloch, 1999) showed emissions 2.3 times larger than emissions determined by flux-gradient (Harper et al., 2001). During winter, the Gaussian model gave emissions 2.6 times higher. On an annual basis (summer winter, and spring emissions) the average emissions were 2.7 times higher than the flux-gradient emissions determined on the same lagoon.

It should be noted that at the present time there is no exact model of turbulent dispersion in the atmospheric boundary layer. Dispersion models exist that are more rigorous than Gaussian models, but they require a much more extensive description of the wind field, and in the case of nonuniform terrain or non-stationary conditions, even the more sophisticated models are subject to unknown and probably large errors. Gaussian models are a compromise requiring minimal input data and consuming minimal computer time. 


\section{ISOTOPE AND OTHER TRACER METHODS}

Tracers have been used extensively to increase our understanding of $\mathrm{N}$ cycling in soil-plant systems and for use in evaluating emissions from soil, plant, or aqueous systems. Caution must be used for $\mathrm{NH}_{3}$ transport studies because of intimate linkages among its various forms. Nitrogen in agricultural production is particularly sensitive to biological and chemical transformations.

\section{Nitrogen Isotopes}

Early studies on fertilizer efficiency and predictions of $\mathrm{NH}_{3}$ loss from fertilizers were determined using stable $\mathrm{N}$ isotopes $\left({ }^{15} \mathrm{~N}\right)$. Although $\mathrm{NH}_{3}$ emissions have been found in cropping systems to be significant in many circumstances, net $\mathrm{N}$ loss as $\mathrm{NH}_{3}$ has been found to be smaller than losses using isotopic techniques (Harper \& Sharpe, 1998). Schjorring et al. (1989) and Francis et al. (1993) showed a decline of labeled $\mathrm{N}$ in the aerial parts of plants during the growing season but Catchpoole et al. (1983) showed that $\mathrm{NH}_{3}$ volatilized from surface-applied urea fertilizer could be directly absorbed by the surrounding grass (Setaria sphacelata Nandi) canopy. In this study, isotope plots were fertilized at the same rate and time as the surrounding pasture. They found that the largest recovery of ${ }^{15} \mathrm{NH}_{3}$ by the surrounding grass occurred when the tropical grass activity was highest (in summer and spring). They also found that the highest apparent loss of fertilizer, compared with micrometeorological methods where net emissions were measured, occurred during periods of highest plant activity (2.4 times higher apparent losses than net losses). They found that when the grass sward was dormant, $\mathrm{NH}_{3}$ losses estimated from ${ }^{15} \mathrm{~N}$ mass balance $(45 \%$ loss) were not significantly different from losses ( $42 \%$ loss) measured using micrometeorlogical techniques (Harper et al., 1983). Thus, in studies similar to these, the use of only ${ }^{15} \mathrm{~N}$ to measure $\mathrm{N}$-use and $\mathrm{NH}_{3}$ volatilization would indicate erroneously large losses of fertilizer $\mathrm{N}$ and much lower plant $\mathrm{N}$-use efficiency.

In another study, $\mathrm{N}$ cycling in wheat (Triticum aestivum $\mathrm{L}$.) showed that $\mathrm{NH}_{3}$ can be absorbed and emitted from the same crop during the same year (Sharpe et al., 1988). They found that during a period of maximum vegetative production, soil mineral $\mathrm{N}$ dropped to very low concentrations resulting in a crop $\mathrm{N}$ use higher than soil mineralization and fertilizer $\mathrm{N}$ release rates. Micrometeorological measurements showed an $\mathrm{NH}_{3}$ absorption flux from the atmosphere to the plants at about the same rate as the difference in plant use and soil N availability rates (Harper et al., 1987). In other studies, Francis (1995, personal communication) observed simultaneous $\mathrm{NH}_{3}$ emission from the ear leaf of corn (Zea mays L.) while absorption occurred in the upper leaves. Because $\mathrm{NH}_{3}$ can be both absorbed and emitted, ${ }^{15} \mathrm{NH}_{3}$ in a growing plant will be lost and substituted for ${ }^{14} \mathrm{NH}_{3}$, even if the net flux is zero. Francis and collaborators (1994, personal communication), using ${ }^{15} \mathrm{~N}$ in a similarly managed cornfield adjacent to a study by Harper and Sharpe (1995), suggested about $23 \mathrm{~kg} \mathrm{~N} \mathrm{ha}^{-1}$ was lost as volatile $\mathrm{NH}_{3}$ during the maturation phase of the corn canopy. Overall for the growing season, using micrometeorological techniques, they found a net loss of $3.6 \mathrm{~kg} \mathrm{~N} \mathrm{ha}^{-1}$, about one-sixth of the $\mathrm{NH}_{3}$ emissions estimated by the iso- 
tope techniques. Legumes have been found (Harper \& Sharpe, 1998) not to emit $\mathrm{NH}_{3}$ from the foliage as long as there is any plant activity. They found (Harper et al., 1989) using both ${ }^{15} \mathrm{~N}_{2}$ gas for fixation measurement in soybeans [Glycine $\max$ (Merr.) L.] and micrometeorological techniques for $\mathrm{NH}_{3}$ flux measurements that 6 to $9 \%$ of the total estimated $\mathrm{N}$ 'fixation' was actually absorbed atmospheric $\mathrm{NH}_{3}$. In a greenhouse study, Sharpe and Harper (1997) found that about $27 \%$ of the ${ }^{15} \mathrm{NH}_{3}$ emitted from treated plants was absorbed by control plants not treated with ${ }^{15} \mathrm{~N}$.

Consequently, use of $\mathrm{N}$ isotopes to estimate $\mathrm{NH}_{3}$ loss may be permissible if there is no plant activity for absorption and desorption. If there is plant activity, micrometeorological techniques must be concurrently used to evaluate the isotope substitution and fractionation.

\section{Tracer-Gases}

A ratioing technique is often used for comparing known tracer-gas emission rates with unknown gas emissions rates (Eklund \& LaCosse, 1995; Todd et al., 2001). The limitations and assumptions inherent in this measurement approach must be recognized when using this technique. They include the following: (i) The tracer gas must adequately simulate the emission source [Note: a potential error is introduced due to the assumption that the point or area release of the tracer gas, which may be lighter or heavier than air, mimics the area $\mathrm{NH}_{3}$ emissions which is itself lighter or heavier than air (McColloch, 1999)], (ii) The vertical distribution of the tracer gas emissions must not be different from that of the unknown emission plume from the measurement area (Eklund \& LaCosse, 1995), and (iii) The horizontal distribution of the tracer is not different from that of the unknown emission plume. This technique does not use plume dispersion models nor other meteorological measurements such as stability corrections. Other uses of tracer techniques have been to release and evaluate known amounts of the gas to be determined prior to the measurements themselves. Denmead et al. (1998a) found that using $\mathrm{CH}_{4}$ as a tracer released to simulate emissions from a point source (such as from a cow) that under windspeeds of less than one to $1.5 \mathrm{~m} \mathrm{sec}^{-1}$, much of the released $\mathrm{CH}_{4}$ was lost to the atmosphere above the measurement height (see discussion of MMD technique). This problem had the effect of biasing the rates low. For gases such as commonly-used sulfur hexaflouride $\left(\mathrm{SF}_{6}\right)$ and carbon tetrafloride $\left(\mathrm{CF}_{4}\right)$, which are heavier than air, if the tracer gas plume tended to remain closer to the ground than the source plume, the measured tracer gas concentrations would be relatively lower and the calculated source emission rates would be biased high (Eklund \& LaCosse, 1995). Results using these tracers have tended to be higher than comparable measurements or reasonable results. Ammonia emissions determined on a lagoon in Texas (Eklund $\&$ LaCosse, 1995) were larger than the amount of $\mathrm{N}$ fed to the animals. In a transport technology comparison study $\mathrm{NH}_{3}$ emissions determined using tracers in a North Carolina lagoon (Todd et al., 2001) gave results about 2.3 times higher than chamber studies (Aneja et al., 1999) and 3.6 times higher than flux-gradient studies (Harper et al., 2001). 


\section{EMISSIONS}

\section{Emissions Measurements}

Emission factors have been used to calculate $\mathrm{NH}_{3}$ emissions from animal husbandry in Europe (Asman, 1992) and the USA (Battye et al., 1994). Table 15-1 presents a list of USA and European emission factors based on a "per animal per year" basis. The factors are quite variable because there are not clear-cut links between countries and their studies (Battye et al., 1994), between measurement technologies, components included (housing, storage, application), and animal categories. Consequently, emission factors must be used with caution because of variability induced by geography and meteorology, methodology for measurement (Denmead \& Raupach, 1993; Harper, 1988), type and weight of animals (Harper et al., 1998), N content of feedstuffs, housing and management, and other factors. Asman (1992) developed a composite factor for Europe of 4.4 $\mathrm{kg} \mathrm{NH}_{3}-\mathrm{N}_{\text {animal }}{ }^{-1}$ year $^{-1}$. Later evaluations by van der Hoek and Couling (1995) separated animals into classes and gave slightly higher emissions for farrow-tofinishing (FF) animals of 5.3, and considerably higher factor of 13.5 for farrowto-wean (FW) animals. Battye et al. (1994), using emissions from Europe and USDA Agricultural Statistics Service animal classifications, developed a similar composite factor to that of Asman (1992) for the USA of $9.2 \mathrm{~kg} \mathrm{NH}_{3}-\mathrm{N} \mathrm{animal}^{-1}$ year $^{-1}$ which is considerably higher than the European factors or the earlier

Table 15-1. USA and Europe swine production emission factors.

\begin{tabular}{lcl}
\hline Source & $\begin{array}{c}\text { Emission factor } \\
\mathrm{kg} \mathrm{NH}_{3}-\mathrm{N} \text { animal }\end{array} \mathrm{yr}^{-1}$ & \multicolumn{1}{c}{ Region } \\
\hline Asman, 1992 & 4.4 & Europe \\
Buijsman et al., 1987 & 1.9 & Europe \\
Cass et al., 1982 & 3.7 & Europe \\
Jarvis \& Pain, 1990 & 3.6 & Europe \\
Kruse et al., 1989 & 2.9 & Europe \\
van der Hoek \& Couling, 1995 & & \\
$\quad$ Farrow to Finish & 0.7 & Europe (composite) \\
$\quad$ Farrow to Wean & $1.8 \dagger$ & Europe (composite) \\
$\quad$ Farrow to Finish & 5.3 & Europe (composite) \\
$\quad$ Farrow to Wean & 13.5 & Europe (composite) \\
Aneja et al., 1999 & $1.8 \dagger$ & \\
$\quad$ Farrow to Finish & 9.2 & USA (NC10-chambers) \\
Battye et al., 1994 & 517.6 & USA (composite) \\
Eklund \& LaCosse, 1995 & & USA (TX-tracer studies) \\
Harper et al., 2000 & & \\
$\quad$ Farrow to Finish & $1.3 \dagger$ & USA (GA1) \\
$\quad$ Primary lagoon & $2.1 \dagger$ & USA (GA) \\
$\quad$ Four-stage lagoons & $3.0 \ddagger$ & Netherlands \\
Voorburg \& Monteny, 1991 & 1.3 & USA \\
Warn et al., 1990 & & \\
Harper \& Sharpe, 2004a & $0.8 \dagger$ & USA (NC10) \\
$\quad$ Farrow to Finish & $1.2 \dagger$ & USA (NC20) \\
$\quad$ Farrow to Wean & &
\end{tabular}

$\uparrow$ Storage only.

$\ddagger$ Per fattening place. 
NAPAP factors (Warn et al., 1990) [There is some question that the Northern European emission factors (Asman, 1992) were used improperly and the U.S. factors developed may be too large by about a factor of two (Asman \& Harper, 2000, personal communication)]. Comparison of lagoon emission factors for FF management systems were similar for van der Hoek and Couling (1995) in Europe, for Harper et al. (2000b) in Georgia (the primary lagoon only, GA1), and for Harper et al. (2001) in North Carolina. Even emission factors determined from the same lagoon using different technologies have shown considerable variation (Table 15-2). On a highly-studied farm in the Coastal Plains of North Carolina (designated $\mathrm{NC10}$ ), several studies of $\mathrm{NH}_{3}$ emissions were compared. Aneja et al. (1999), using floating chambers obtained an estimate of lagoon annual emissions of 2.7 times larger than those of Harper et al. (2001) using microclimate techniques for the same lagoon.

McColloch (1999), using a Gaussian model, determined annual emissions of 2.3 times higher than Harper et al. (2001) whereas Todd et al. (2001), using tracer techniques, obtained annual emissions 4.7 times that of Harper et al. (2001). For that farm, a total $\mathrm{N}$ balance of individually-measured components (Fig. 15-9) accounted for about 95\% of the input $\mathrm{N}$ as feed (Harper et al., 2004a).

Measurement of emissions from animal housing also show some variability. Harris and Thompson (1998) determined barn annual average emissions on the NC10 farm (using FTIR and estimates of fan flow rates) of $3.7 \mathrm{~kg} \mathrm{NH}_{3} \mathrm{an}^{-1}$ $\mathrm{yr}^{-1}$. Direct fan flow-rate measurements and TDL spectroscopy by Harper et al. (2004b) gave emissions of $2.7 \mathrm{~kg} \mathrm{NH}_{3} \mathrm{an}^{-1} \mathrm{yr}^{-1}$ on the same swine houses. Estimates by van der Hoek (1998) gave remarkably similar emissions (to that of Harper et al., 2004b) of $2.9 \mathrm{~kg} \mathrm{NH}_{3} \mathrm{an}^{-1} \mathrm{yr}^{-1}$ from swine houses in Europe. It should be noted, however, that emissions may be very different for different animal types and seasons. Harper et al. (2004b) showed about twice as high $\mathrm{NH}_{3}$ emissions from housing in summer than in winter but also showed considerable difference between animal types. They found that finishing pigs emitted about eight times as much $\mathrm{NH}_{3}$ per animal as farrowing sows (including nursing

Table 15-2. Comparison of lagoon emissions determined by different techniques on a swine production farm in North Carolina.

\begin{tabular}{llccc}
\hline Method & Season & $\begin{array}{c}\text { Lagoon emissions } \\
\mathrm{kg} \mathrm{NH}_{3}-\mathrm{N} \mathrm{ha}^{-1} \mathrm{yr}^{-1}\end{array}$ & $\begin{array}{c}\text { Housing emissions } \\
\mathrm{kg} \mathrm{NH}_{3}-\mathrm{N}_{\text {animal }}^{-1} \mathrm{yr}^{-1}\end{array}$ & Reference \\
\hline Chambers & Summer & 57.8 & & Aneja et al., 1999 \\
Flux-gradient & Summer & 18.7 & Harper et al., 2001 \\
$\begin{array}{l}\text { Gaussian model } \\
\text { Tracers }\end{array}$ & Summer & 42.3 & McCulloch, 1999 \\
Chambers & Summer & 96 & Todd et al., 2001 \\
$\begin{array}{l}\text { Flux-gradient } \\
\text { Gaussian model }\end{array}$ & Winter & Winter & 12.2 & Aneja et al., 1999 \\
Tracers & Winter & 19.6 & Harper et al., 2001 \\
$\begin{array}{l}\text { Mass balance } \\
\text { (direct fan }\end{array}$ & Annual & 27.5 & McCulloch, 1999 \\
measurements) & & & Todd et al., 2001 \\
$\begin{array}{l}\text { Mass balance } \\
\text { (estimated fan }\end{array}$ & Annual & & 3.7 & Harper et al., 2001 \\
flow) & & & Harris \& \\
\hline
\end{tabular}




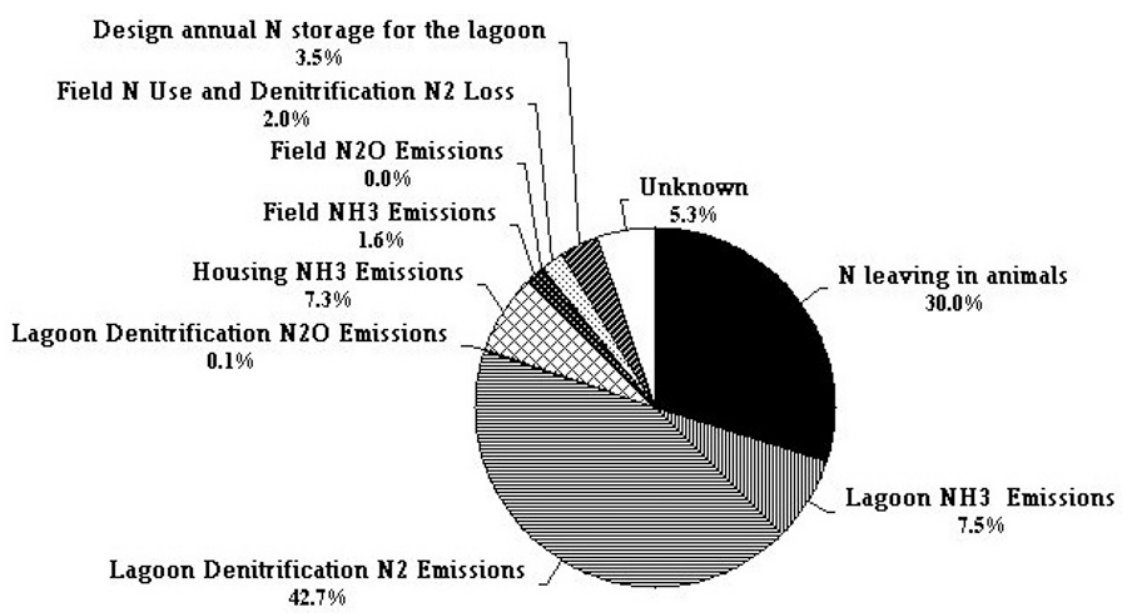

Fig. 15-9. Mass-balance of individually-measured N components in a North Carolina (NC 10) swine farm (after Harper et al., 2004a).

piglets), but on a per kilogram weight basis, finishers produced about 1.8 times as much $\mathrm{NH}_{3}$ from houses as did farrowing sows and piglets. Similar differences and variabilities in emissions have been found for emissions from crops using different measuring methods, different crop species, and different crop growth stages (see Appendix, Holtan-Hartwig \& Bockman, 1994).

General emission factors are requested by planners, designers, and regulators to estimate $\mathrm{NH}_{3}$ and other trace gas emissions and these comparisons show the inherent dangers of basing emissions on animal numbers and not accounting for climatic, animal class, or management considerations. Other differences in published emissions factors can be explained, based on technologies of measurement.

\section{COMPARISON OF TECHNIQUES}

Table 15-3 gives a comparison of many of the techniques found in the literature. More complete discussions of accuracies, problems, and strengths of the techniques may be found in individual discussions (see Methods of Measurement). The IHF is generally considered to be the most physically-correct technique and may be considered to be a standard for making comparisons where possible. Another technique, stable $\mathrm{N}$ isotopes, using short-term measurements in the absence of plant activity also may be used as a good comparison. Fluxgradient techniques have been used extensively and successfully in many agricultural situations but a study (Harper et al., 1973) using $\mathrm{CO}_{2}$ as a tracer, showed the necessity for a thermal stability correction using the momentum balance technique for determination of the transfer coefficient. A relatively-new technique, bLS, looks promising and further research should indicate its value and utility in trace-gas research and evaluation. Recent studies (L.A. Harper et al., 2005, 


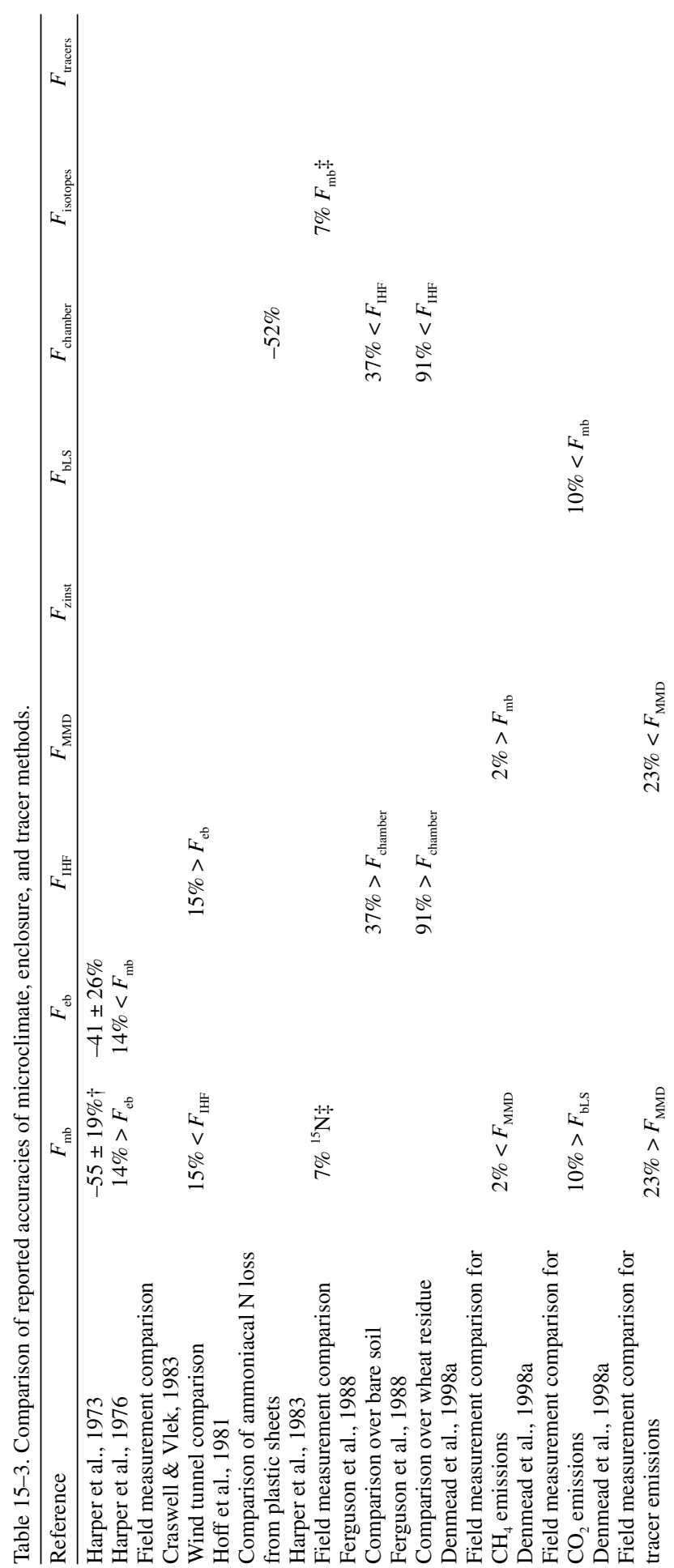




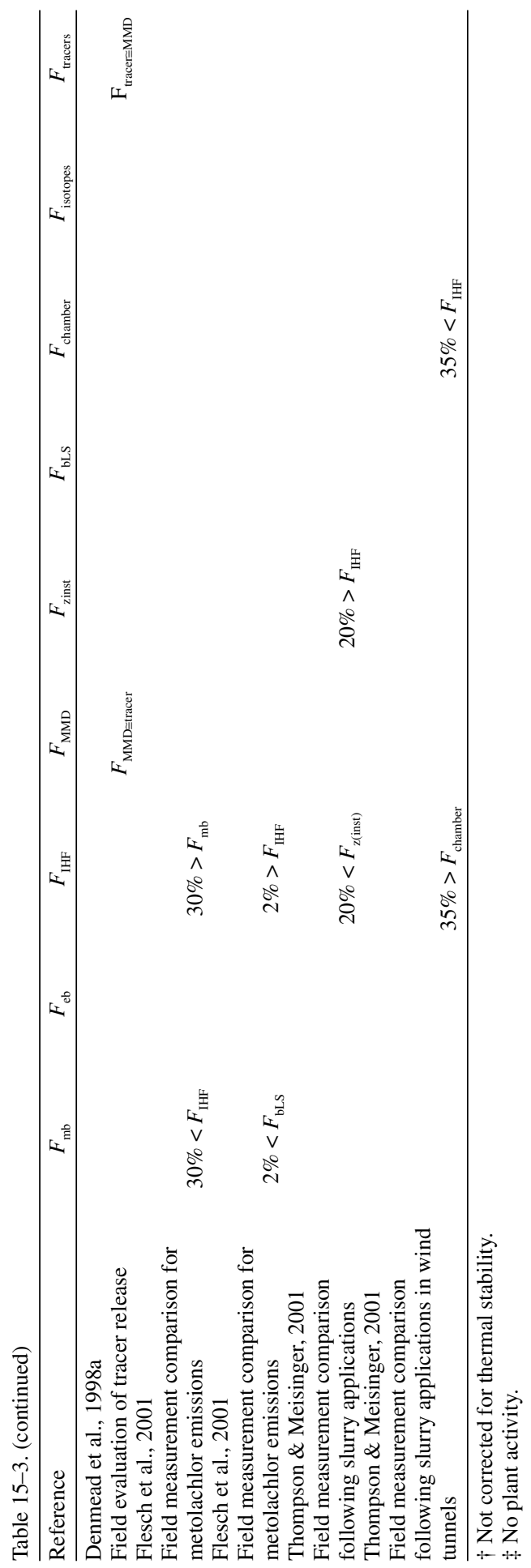


unpublished data) have shown no significant difference between flux-gradient (using momentum balance with Schmidt corrections) and bLS $\mathrm{NH}_{3}$ emissions in a large beef feedlot of 50000 animals. While closed-chamber techniques are useful for making relative comparisons of nonreactive gases, because of the nature of reactive and diffusive gases and the effect of turbulence on their transport processes, such as $\mathrm{NH}_{3}$ and $\mathrm{HF}$, the use of closed chambers are not appropriate. The use of wind tunnel type chambers is an improvement compared with closedchamber techniques and are quite useful for making treatment comparisons, but they are still not appropriate for determination of absolute emissions. Table 15-1 compares the variabilities in measurements of $\mathrm{NH}_{3}$ emissions in swine production systems among researchers, part of which is due to different measurement techniques. Table 15-2 exemplifies problems associated with obtaining accurate emissions using different technologies on the same lagoon. Consequently, the research, regulatory, or monitoring organization must be cautious of $\mathrm{NH}_{3}$ emissions obtained where possible inappropriate methodologies and sensors have been used.

\section{SUMMARY}

Because of its chemical properties, $\mathrm{NH}_{3}$ is a difficult gas to measure without disturbing its transport characteristics. Ammonia is a highly reactive, absorptive, and sticky gas requiring great care in sampling. Its chemical properties dictate the use of transport technologies that do not interfere with the source temperature, concentration, $\mathrm{pH}$, and turbulent or diffusive transport. Its chemical measurement necessitates precautions since it may adsorb and desorb with most surfaces and with the sensors themselves. The purpose of this chapter has been to review available atmospheric-exchange and transport technology and discuss strengths and weaknesses of the methodologies.

Measurement of $\mathrm{NH}_{3}$ transport with closed chamber systems is generally not recommended unless the systems are specifically defined and the information will be used only for comparative differences. If used, during the measurement process careful attention must be given to equilibration before measurement is begun. Ambient transport conditions can be approached using wind-tunnel chambers and this technique is useful in obtaining relative comparisons. Absolute emissions should be evaluated using non-interference techniques if at all possible.

There are a number of micrometeorological techniques and all have their strengths and weaknesses. The flux-gradient, eddy covariance, and relaxed eddy accumulation techniques are noninterfering and integrate large spatial source areas but have relatively large fetch requirements of at least 100:1 upwind distance to measurement height. Mass-balance techniques are more physically correct and are useful for relatively small source areas of less than a hectare. The Lagrangian dispersion analysis technique has been useful in evaluating source and sink strengths and absolute emissions have been shown to be comparable to other micrometeorological techniques. The backward Lagrangian stochastic analysis technique shows promise as a noninterference evaluation technology but is currently not proven except in the simplest atmospheric transport (or disturbance) situation. 
The contribution of $\mathrm{N}$ compounds to the total deposition of pollutants is becoming more important. Nitrogen is difficult to abate because of the intimate linkages among its various forms and among agriculture, industry, and transportation emissions. Within agriculture, reducing $\mathrm{NH}_{3}$ emissions may increase $\mathrm{N}_{2} \mathrm{O}$ and $\mathrm{NO}_{3}$ and in transportation, reducing $\mathrm{NOx}$ emissions is leading to increased $\mathrm{NH}_{3}$ and $\mathrm{N}_{2} \mathrm{O}$ emissions. The global population is expected to grow continuously while the agricultural area used for food production cannot increase indefinitely. Therefore, the use of $\mathrm{N}$ to increase agricultural production is expected to grow considerably. The prospects for emissions reduction may consequently be limited. Therefore, correct and accurate measurements of $\mathrm{NH}_{3}$ emissions are needed to address linkages in the environment.

\section{REFERENCES}

Aneja, V.P., J.P. Chauhan, and J.T Walker. 1999. Characterization of ammonia emissions from swine waste lagoons. Final Rep. to DAQ, NCDENR, Contract no. EA8001 and Water Resources Research Institute, Contract no. EA7003. North Carolina State Univ., Raleigh.

Arya, S.P. 1999. Air pollution meteorology and dispersion. Oxford Univ. Press, New York.

Asman, W.A.H. 1992. Ammonia emissions in Europe: Updated emission and emission variations. Rep. no. 228471008. Natl. Inst. of Public Health and Environ. Protec., Bilthoven, the Netherlands.

Asman, W.A.H. 1994. Emission and deposition of ammonia and ammonium. Nova Acta Leopold. 70:263-297.

Asman, W.A.H., P. Cellier, S. Genermont, N.J. Hutchins, and S.G. Sommer. 1998. Ammonia emission research: From emission factors to process descriptions. EUROTRAC Newsl. 20:2-10.

Battye, R., W. Battye, C. Overcash, and S. Fudge. 1994. Development and selection of ammonia emission factors. USEPA Contract no. 68-D3-0034. Work Assign. 0-3. USEPA, Research Triangle Park, NC.

Bauer, J., J. Tulip, P. Kain, M. Paulson, and J. Ondrak. 1999. Results of the application of a new laser based open-path spectrometer for the measurement of fugitive emissions from gas processing plants. p. 186-196. In Proc. Conf. on Optical Sensing for Environmental and Process Monitoring, Nov. 6-8. Air and Water Waste Management Assoc., Dallas, TX.

Bouwman, A.F., D.S. Lee, W.A.H. Asman, F.J. Dentener, K.W. Van Der Hoek, and J.G.J. Olivier. 1997. A global high-resolution emission inventory for ammonia. Global Biogeochem. Cycles. 11:561-587.

Craswell, E.T., and P.L.G. Vlek. 1983. Fate of fertilizer nitrogen applied to wetland rice. p. 237-264. In J.R. Freney and J.R. Simpson (ed.) Gaseous loss of nitrogen from plant-soil systems. Martinus Nijhoff/Dr. Junk, the Hague, the Netherlands.

Buijsman, E., H.F.M. Maas, and W.A.H. Asman. 1987. Anthropogenic $\mathrm{NH}_{3}$ emissions in Europe. Atmos. Environ. 21:1009-1022.

Businger, J.A. and S.P. Oncley. 1990. Flux measurement with conditional sampling. J. Atmos. Ocean. Technol. 7:349-352.

Bussink, D.W., L.A. Harper, and W.J. Corre. 1996. Ammonia transport in a temperate grassland: II. Diurnal fluctuations in response to weather and management conditions. Agron. J. 88:621-626.

Cass, G.R. 1982. The origin of ammonia emission to the atmosphere in an urban area. Open File Rep. 82-6. Environ. Qual. Lab., California Inst. of Technol., Los Angeles.

Catchpoole, V.R., D.J. Oxemham, and L.A. Harper. 1983. Transformation and recovery of urea applied to a grass pasture in south-eastern Queensland. Aust. J. Agric. Anim. Husb. 23:80-86.

Czepiel, P.M., B. Mosher, R.C. Harriss, J.H. Shorter, J.B. McManus, C.E. Kolb, E. Allwind, and B.K. Lamb. 1996. Landfill methane emissions measured by enclosure and atmospheric tracer methods. J. Geophys. Res. 101:16 711-16 719.

Denmead, O.T. 1983. Micrometeorological methods for measuring gaseous losses of nitrogen in the field. p. 133-157. In J.R. Freney and J.R. Simpson (ed.) Gaseous loss of nitrogen from plant-soil systems. Martinus Nijhoff/Dr. Junk, the Hague, the Netherlands.

Denmead, O.T., R.L. Desjardins, L.A. Harper, L.O. Savard, S. Kaharabata, and J. Scarbrough. 2003. A mass balance method for measuring methane emissions from animal operations using openpath lasers. ASA, Madison, WI. 
Denmead, O.T., J.R. Freney, and J.R. Simpson. 1976. A closed ammonia cycle within a plant canopy. Soil Biol. Biochem. 8:161-166.

Denmead, O.T., J.R. Freney, and J.R. Simpson. 1982. Dynamics of ammonia volatilization during furrow irrigation of maize. Soil Sci. Soc. Am. J. 46:149-155.

Denmead, O.T., D.W.T. Griffith, R. Leuning, and F. Turatti. 1998a. Direct measurements of methane and nitrous oxide emissions from a landfill: Verifying inventory methodologies. p. 1-25. In O.T. Denmead et al. (ed.) Verifying current estimates of non- $\mathrm{CO}_{2}$ greenhouse gas emissions from animals, landfills, and pastures with direct measurements. Final Rep. to National Greenhouse Gas Inventory Committee, Consultancy Rep. no. 98-62. CSIRO, Canberra, Australia.

Denmead, O.T., L.A. Harper, J.R. Freney, D.W.T. Griffith, R. Leuning, and R.R. Sharpe. 1998b. A mass balance method for non-intrusive measurements of surface-air trace gas exchange. Atmos. Environ. 32:3679-3688.

Denmead, O.T., L.A. Harper, and R.R. Sharpe. 2000a. Identifying sources and sinks of scalars in a corn canopy with inverse Lagrangian dispersion analysis: I. Heat. Agric. For. Meteorol. 104:75-83.

Denmead. O.T., R. Leuning, D.W.T. Griffith, I.M. Jamie, M.B. Esler, L.A. Harper, and J.R. Freney. 2000c. Verifying inventory predictions of animal methane emissions with micrometeorological measurements. Boundary-Layer Meteorol. 96:187-209.

Denmead, O.T, R. Leuning, I.M. Jamie, and E.W.T. Griffith. 2000b. Nitrous oxide emissions from grazed pastures: Measurements at different scales. Chemosphere-Global Change Sci. 2:301-312.

Denmead, O.T., R. Nulsen, and G.W. Thurtell. 1978. Ammonia exchange over a corn crop. Soil Sci. Soc. Am. J. 42:840-842.

Denmead, O.T., and M.R. Raupach. 1993. Methods for measuring atmospheric gas transport in agricultural and forest systems. p. 19-43. In L.A. Harper et al. (ed.) Agricultural ecosystem effects on trace gases and global climate change. ASA Spec. Publ. no. 55. ASA, Madison, WI.

Denmead, O.T., J.R. Simpson, and J.R. Freney. 1974. Ammonia flux into the atmosphere from a grazed pasture. Science (Washington, DC) 185:609-610.

Desjardins, R.L. 1972. A study of carbon dioxide and sensible heat fluxes using the eddy correlation technique. Ph.D. Diss. Cornell Univ., Ithaca, NY (Diss. Abstr. 73-34).

Desjardins, R.L., D. Buckley, and G. St.-Amour. 1984. Eddy flux measurement of $\mathrm{CO}_{2}$ using a microcomputer system. Agric. For. Meteorol. J. 32:257-265.

DeVisscher, A., L.A. Harper, P.W. Westerman, R.R. Sharpe, and O. Van Cleemput. 2002. Ammonia emissions from anaerobic swine lagoons: Model development. J. Appl. Meteorol. 41:426-433.

Diaz, G.T., G.W. Thurtell, C. Wagner-Riddle, and L.A. Harper. 1996. Measuring ammonia fluxes from soil with a laser-based trace gas analyzer. In Proc. of the Int. Conf. on Air Pollutio from Agricultural Operations, Kansas City, MO.

Dickson, R.J. 1991. Development of the ammonia emission inventory for the southern California Air Quality Study. Rep. to the Electric Power Res. Inst. under Grant no. 2333-4. Radian Corp., Sacramento, CA.

Eklund, B., and J. LaCosse. 1995. Field measurements of greenhouse gas emissions from the wastewater treatment systems at two farms. Radian Corp. Rep. to USEPA, USEPA Contract no. 68D1-0031, Work Assignment 66. USEPA, Research Triangle Park, NC.

Farquhar, G.D., R. Wetselaar, and B. Weier. 1983. Gaseous nitrogen losses from plants. p. 159-180. In J.R. Freney and J.R. Simpson (ed.), Gaseous loss of nitrogen from plant-soil systems. Martinus Nijhoff/Dr. Junk, the Hague, the Netherlands.

Ferguson, R.B., K.J. McInnes, D.E. Kissel, and E.T. Kanemasu. 1988. A comparison of methods of estimating ammonia volatilization in the field. Fert. Res. 15:55-69.

Flesch, T.K., and J.D. Wilson. 2005. Estimating tracer emissions with a backward Lagrangian stochastic technique. p. 493-511. In J.L. Hatfield and J.M. Baker (ed.) Micrometeorology in agricultural systems. ASA Monogr. 47. ASA, CSSA, and SSSA, Madison, WI (this volume).

Flesch, T.K., J.D. Wilson, L.A. Harper, B.P. Crenna, and R.R. Sharpe. 2004. Deducing ground-air emissions from observed trace-gas concentrations: A field trial. Am. Meteorol. Soc. 43:487-502.

Flesch, T.K, J.D. Wilson, L.A. Harper, R.R. Sharpe, and B.P. Crenna. 2002. Tracer emissions inferred from a backward Lagrangian stochastic dispersion model: A validation study. p. 162-163. In Proc. 25th Am. Meteorol. Soc. on Agric. and For. Meteorol., May 20-24. Am. Meteorol. Soc., Norfolk, VA.

Flesch, T.K., J.D. Wilson, and E. Yee. 1995. Backward-time Lagrangian stochastic dispersion models, and their application to estimate gaseous emissions. J. Appl. Meteorol. 34:1320-1332.

Folorunso, O.A., and D.E. Rolston. 1984. Spatial variability of field-measured denitrification gas fluxes. Soil Sci. Soc. Am. J. 48:1214-1219. 
Fox, R.H., W.P. Plekletek, and K.E. Macneal. 1996. Estimating ammonia volatilization losses from urea fertilizers using a simplified micrometeorological sampler. Soil Sci. Soc. Am. J. 60:596-601.

Francis, D.D., J.L. Schepers, and MF. Vigil. 1993. Post-anthesis nitrogen loss from corn. Agron. J. 85:659-663.

Fritschen, L.J., and C.L. Fritschen. 2005. Bowen ratio energy balance method. p. 377-385. In J.L. Hatfield and J.M. Baker (ed.) Micrometeorology in agricultural systems. ASA Monogr. 47. ASA, CSSA, and SSSA, Madison, WI (this volume).

Fraser, M.P., and G.R. Cass. 1998. Detection of excess ammonia emissions from in-use vehicles and the implications for fine particle control. Environ. Sci. Technol. 32:1053-1057.

Freney, J.R., O.T. Denmead, I. Watanabe, and E.T. Craswell. 1981. Ammonia and nitrous oxide losses following applications of ammonium sulfate to flooded rice. Aust. J. Agric. Res. 32:37-45.

Freney, J.R., O.T. Denmead, A.W. Wood, P.G. Saffigna, L.S. Chapman, G.J. Ham, A.P.Hurney, and R.L. Stewart. 1992. Factors controlling ammonia los from trash covered sugarcane fields fertilized with urea. Fert. Res. 31:341-349.

Freney, J.R., J.R. Simpson, and O.T. Denmead. 1983. Volatilization of ammonia. p. 1-32. In J.R. Freney and J.R. Simpson (ed.) Gaseous losses of nitrogen from plant-soil systems. Martinus Nijhoff/Dr. Junk, the Hague, the Netherlands.

Galbally, I.E., C.M. Elsworth, and H.A.H. Rabich. 1985. The measurement of nitrogen oxide (NO, $\mathrm{NO}_{2}$ ) exchange over plant/soil surfaces. CSIRO Div. Atmos. Res. Technol. Pap. 8:1-23.

Galle, B., L. Klemedtsson, and D.W. Griffith. 1994. Application of an FTIR system for measurements of nitrous oxide fluxes using micrometeorological methods, and ultra-large chamber system and conventional field chambers. J. Geophys. Res. 99:16 575-16 583.

Galloway, J.N. 1995. Acid deposition: Perspectives in time and space. Water Air Soil Pollut. 85:15-24.

Hargrove, W.L., B.R. Bock, R.A. Raunikar, and W.J. Urban. 1987. Comparison of a force-draft technique to nitrogen-15 recovery for measuring ammonia volatilization under field conditions. Soil Sci. Soc. Am. J. 51:124-128.

Harper, L.A. 1988. Comparisons of methods to measure ammonia volatilization in the field. p. 93-109. In B.R. Bock and D.E. Kissel (ed.). Ammonia volatilization from urea fertilizers. Tennessee Valley Authority, Muscle Shoals, AL.

Harper, L.A., J.E. Box, Jr., D.N. Baker, and J.D. Hesketh. 1973. Carbon dioxide and the photosynthesis of field crops. A tracer examination of turbulent transfer theory. Agron. J. 65:574-578.

Harper, L.A., D.W. Bussink, H.G. van der Meer, and W.J. Corre. 1996. Ammonia transport in a temperate grassland: I. Seasonal transport in relation to soil fertility and crop management. Agron. J. 88:614-621.

Harper, L.A., V.R. Catchpoole, R. Davis, and K.L. Weier. 1983. Ammonia volatilization: Soil, plant, and microclimate effects on diurnal and seasonal fluctuations. Agron. J. 75:212-218.

Harper, L.A., O.T. Denmead, J.R. Freney, and F.M. Byers. 1998. Direct measurements of methane emissions from grazing and feedlot cattle. In O.T. Denmeadet al. (ed.). Verifying current estimates of non- $\mathrm{CO}_{2}$ greenhouse gas emissions from animals, landfills and pastures with direct measurements. Final Rep. to the National Greenhouse Gas Inventory Committee, Government of Australia. CSIRO Land and Water Consultancy Rep. 98-62. CSIRO, Canberra, Australia.

Harper, L.A., O.T. Denmead, J.R. Freney, and F.M. Byers. 1999. Direct measurements of methane emissions from grazing and feedlot cattle. J. Anim. Sci. 77:1392-1401.

Harper, L.A., O.T. Denmead, and R.R. Sharpe. 2000a. Identifying sources and sinks of scalars in a corn canopy with inverse Lagrangian dispersion analysis: II. Ammonia. Agric. For. Meteorol. 104:75-83.

Harper, L.A., J.E. Giddens, G.W. Langdale, and R.R. Sharpe. 1989. Environmental effects on nitrogen dynamics in soybeans under conservation and clean tillage systems. Agron. J. 81:623-31.

Harper, L.A., and R.R. Sharpe. 1995. Nitrogen dynamics in irrigated corn: Soil-plant nitrogen and atmospheric ammonia transport. Agron. J. 87:669-675.

Harper, L.A., and R.R. Sharpe. 1998. Ammonia emissions from swine waste lagoons in the southeastern U.S. Coastal Plains. Final Grant Rep. to Division of Air Quality, North Carolina Department of Environment and Natural Resources, Raleigh, NC. USDA-ARS Agreement no. 58-6612-7M-022. USDA-ARS, Raleigh, NC.

Harper, L.A., R.R. Sharpe, and F.M. Byers. 2001. Nitrogen cycling in swine production systems: Independent measurement techniques for system mass balance. In Proc. 2001 Int. Conf. on Future Directions in Air Quality Research, Feb. 12-15, 2001. North Carolina State Univ., Raleigh.

Harper, L.A., R.R. Sharpe, G.W. Langdale, and J.E. Giddens. 1987. Nitrogen cycling in a wheat crop: Soil, plant, and aerial nitrogen transport. Agron. J. 79:965-973. 
Harper, L.A., R.R. Sharpe, and T.B. Parkin. 2000b. Nitrogen cycling in swine production systems: Ammonia, nitrous oxide, and dinitrogen gas. J. Environ. Qual. 29:1356-1365.

Harper, L.A., R.R. Sharpe, T.B. Parkin, A. De Visscher, O. Van Cleemput, and F.M. Byers. 2004 a. Nitrogen cycling through swine production systems swine production systems: Ammonia, nitrous oxide, and dinitrogen gas. J. Environ. Qual. 33:449-462.

Harper, L.A., R.R. Sharpe, and J.D. Simmons. 2004b. Ammonia emissions from swine production houses. J. Environ. Qual. 33:449-457.

Harper, L.A., A.W. White, Jr., R.R. Bruce, A.W. Thomas, and R.A. Leonard. 1976. Soil and microclimate effects on trifluralin volatilization. J. Environ. Qual. 5:236-242.

Harris, D.B., and E.L. Thompson, Jr. 1998. Evaluation of ammonia emissions from swine operations in North Carolina. Am. Water Manage. Assoc. Publ. VIP-88.

Hicks, B.B. 1972. Propeller anemometers as sensors of atmospheric turbulence. Boundary-Layer Meteorol. 3:214-228.

Hoff, J.D., D.W. Nelson, and A.L. Sutton. 1981. Ammonia volatilization from liquid swine manure applied to crop land. J. Environ. Qual. 10:90-95.

Holtan-Hartwig, L., and O. Bockman. 1994. Ammonia exchange between crops and air. Norwegian J. Agric. Sci., Suppl. No. 14.

Hutchinson, G.L., A.R. Mosier, and C.E. Andre. 1982. Ammonia and amine emissions from a large cattle feedlot. J. Environ. Qual. 11:288-293.

Jarvis, S.C., and B.F. Pain. 1990. Ammonia volatilization from agricultural land. Proc. no. 298. The Fert. Soc., London.

Keuken, M.P., C.A.M. Schoonebeek,A. Wensveen-Louter, J. vanSlanina. 1988. Simultaneous sampling of $\mathrm{NH}_{3}, \mathrm{HNO}_{3}, \mathrm{HCl}, \mathrm{SO}_{2}$, and $\mathrm{H}_{2} \mathrm{O}_{2}$ by a wet annular denuder system. Atmos. Environ. 22:2541-2548.

Kissel, D.E., H.L. Brewer, and G.F. Arkin. 1977. Design and test of a field sampler for ammonia volatilization. Soil Sci. Soc. Am. J. 41:1133-1138.

Koelliker, J.K., and D.E. Kissel. 1988. Chemical equilibria affecting ammonia volatilization. p. 93-109. In B.R. Bock and D.E. Kissel (ed.). Ammonia volatilization from urea fertilizers. Tennessee Valley Authority, Muscle Shoals, AL.

Krause, M., H. ApSimon, and J.N.B. Bell. 1989. Validity and uncertainty in the calculation of an emission inventory for ammonia arising from agriculture in Great Britain. Environ. Pollut. 56:237-257.

Lawes, J.B., and J.H. Gilbert. 1851. On agricultural chemistry. J. Roy. Agric Soc. Eng. 12:1-40.

LeClerc, M.Y., and G.W. Thurtell. 1990. Footprint prediction of scalar fluxes using a Markovian analysis. Boundary-Layer Meteorol. 52:247-258.

Lemon, E.R. 1967. Aerodynamic studies of $\mathrm{CO}_{2}$ exchange between the atmosphere and the plant. p. 263-290. In B.J. Barfield and J. Gerber (ed.) Modification of the aerial environment of crops. ASA Monogr. 2. ASA, CSSA, and SSSA, Madison, WI.

Lemon, E.R., and R. van Houtte. 1980. Ammonia exchange at the land surface. Agron. J. 72:876-883.

Leuning, R., S.K. Baker, I.M. Jamie, C.H. Hsu, L. Klein, O.T. Denmead, and D.W.T. Griffith. 1998. Methane emission from free-ranging sheep: A comparison of two measurement methods. Atmos. Environ. 33:1357-1365.

Leuning, R., J.R. Freney, O.T. Denmead, and J.R. Simson. 1985. A sampler for measuring atmospheric ammonia flux. Atmos. Environ. 19:1117-1124.

Lockyer, D.R. 1984. A system for the measurement in the field of losses of ammonia through volatilisation. J. Sci. Food Agric. 35:837-848.

Majewski, M., R.L. Desjardins, P. Rochette, E. Pattey, J. Seiber, and D. Glotfelty. 1993. Field comparison of an eddy accumulation and an aerodynamic-gradient system for measuring pesticide volatilization fluxes. Environ. Sci. Technol. 27:121-128.

Marshall, V.G., and D.S. Debell. 1980. Comparison of four methods measuring volatilization losses of nitrogen following urea fertilization of forest soils. Can. J. Soil Sci. 60:549-563.

Matthias, A.D., A.M. Blackmer, and J.M. Bremner. 1980. A simple chamber technique for field measurement of emissions of nitrous oxide from soils. J. Environ. Qual. 9:251-256.

Meyer, M.W. 1973. Absorption and release of ammonia from and to the atmosphere by plants. Ph.D. diss. Univ. of Maryland, College Park (Diss. Abstr. 73-28881).

Meyers, T.P., and D.D. Baldocchi. 2005. Current micrometeorological flux methodologies with applications in agriculture. p. 361-376. In J.L. Hatfield and J.M. Baker (ed.) Micrometeorology in agricultural systems. ASA Monogr. 47. ASA, CSSA, and SSSA, Madison, WI (this volume).

McCulloch, R.B. 1999. Estimating ammonia emissions from a swine production facility in North Carolina using an inverted Gaussian plume model. M.S. thesis. North Carolina State University, Raleigh. 
McColloch, R.B., G.S. Few, G.C. Murray, Jr., and V.P. Aneja. 1998. Analysis of ammonia, ammonium aerosols and acid gases in the atmosphere at a commercial hog farm in eastern North Carolina. USA. Environ. Pollut. 102:263-268.

McColloch, R.B., and A.D. Shendrikar. 2000. Concurrent atmospheric ammonia measurements using citric-acid-coated diffusion denuders and a chemiluminescence analyzer. Atmos. Environ. 34:4957-4958.

McCulloch, R.B., J.T. Walker, J.S. Chauhan, and K. Miller. 2001. Performance characteristics and applications of a high-sensitivity ammonia analyzer. In Proc. of Air Quality Research: Future Directions, Ecological, Atmospheric, Regulatory/Policy, and Educational Issues, Feb. 12-15, Research Triangle Park, NC.

McInnes, K.J, R.B. Ferguson, D.E. Kissel, and E.T. Kanemasu. 1986. A field measurement of ammonia loss from surface applications of urea solution to bare soil. Agron. J. 78:192-196.

McInnes, K.J., D.E. Kissel, and E.T. Kanemasu. 1985. Estimating ammonia flux: A comparison between the integrated horizontal flux method and theoretical solution of the diffusion profile. Agron. J. 77:884-889.

Morgan, J.A., and W.J. Parton. 1989. Characteristics of ammonia from spring wheat. Crop Sci. 29:726-731.

Mulhearn, P.J. 1977. Relations between surface fluxes and mean profiles of velocity, temperature and concentration, downwind of a change in surface roughness. Quart. J. Roy. Meteorol. Soc. 103:785-802.

Neftel, A., A. Blatter, A. Gut, D. Hogger, F. Meizner, C. Ammann, and F.J. Nathaus. 1998. Ammonia soil and soil surface gas measurements in a triticale wheat field. Atmos. Environ 32:499-506.

Nihlgard, B. 1985. The ammonium hypothesis: An additional explanation to the forest dieback in Europe. Ambio 14:2-6.

Paerl, H.W. 1995. Coastal eutrophication in relation to atmospheric nitrogen deposition: Current perspectives. Ophelia 41:237-259.

Parton, W.J., J.A. Morgan, J. Altenhofen, and L.A. Harper. 1988. Ammonia volatilization from 'Olaf' spring wheat plants. Agron. J. 80:419-425.

Pattey, E., R.L. Desjardins, and P. Rochester. 1993. Accuracy of the relaxed eddy-accumulation technique, evaluated using $\mathrm{CO}_{2}$ flux measurements. Boundary-Layer Meteorol. 66:341-355.

Perrino, C., and M. Gherardi. 1999. Optimization of the coating layer for the measurement of ammonia by diffusion denuders. Atmos. Environ. 33:4579-4587.

Philip, J.R. 1959. The theory of local advection. I. J. Meteorol. 16:535-547.

Prueger, J.H., and W.P. Kustas. 2005. Aerodynamic methods for estimating turbulent fluxes. p. 387-416. In J.L. Hatfield and J.M. Baker (ed.) Micrometeorology in agricultural systems. ASA Monogr. 47. ASA, CSSA, and SSSA, Madison, WI (this volume).

Rao, K.S., J.C. Wyngaard, and O.R. Cote. 1974. Local advection of momentum, heat, and moisture in micrometeorology. Boundary-Layer Meteorol. 7:331-348.

Raupach, M.R. 1989. A practical Lagrangian method for relating scalar concentrations to source distributions in vegetation canopies. Agric. For. Meteorol. 47:85-108.

Raupach, M.R., O.T. Denmead, and F.X. Dunin. 1992. Challenges in linking atmospheric $\mathrm{CO}_{2}$ concentrations to fluxes at local and regional scales. Aust. J Bot. 40:697-716.

Raupach, M.R., and B.J. Legg. 1984. The uses and limitations of flux-gradient relationships in micrometeorology. Agric. Water Manage. 8:119-131.

Recous, S., C. Fresneau, G. Faurie, and B. Mary. 1988. The fate of labeled ${ }^{15} \mathrm{~N}$ urea and ammonium nitrate applied to a winter wheat crop: I. Nitrogen transformations in the soil. Plant Soil 112:205-214.

Richardson, L.F. 1929. The supply of energy from and to atmospheric eddies. Proc. Roy. Soc. A 97:354-373.

Russell, J.M., R.N. Cooper, and S.B. Lindsey. 1993. Soil denitrification rates at wastewater irrigation sites receiving primary-treated and anaerobically treated meat-processing effluent. Biores. Technol. 43:41-46.

Ryden, J.C., and D.R. Lockyer. 1985. Evaluation of a system of wind tunnels for field studies of ammonia loss from grassland through volatilization. J. Sci. Food Agric. 36:781-788.

Schjoerring, J.K., N.E. Nielsen, H.E. Jensen, and A. Gottschau. 1989. Nitrogen losses from fieldgrown barley plants as affected by rate of nitrogen application. Plant Soil 116:165-175.

Schjoerring, J.K., S.G. Sommer, and M.Ferm. 1992. A simple passive flux sampler for measuring ammonia emission is the field. Water Air Soil Pollut. 62:13-24.

Sharpe, R.R., and L.A. Harper. 1997. Ammonia and nitrous oxide emissions from sprinkler irrigation applications of swine effluent. J. Environ Qual. 26:1703-1706.

Sharpe, R.R., and L.A. Harper. 1999. Methane emissions from an anaerobic swine lagoon. Atmos. Environ. 33:3627-3633. 
Sharpe, R.R., L.A. Harper, J.E. Giddens, and G.W. Langdale. 1988. Nitrogen use efficiency and N budget for conservation tilled wheat. Soil Sci. Soc. Am. J. 52:1394-1398.

Simpson, I.J., G.W. Thurtell, G.E. Kidd, M. Lin, T.H. Demetriades-Shah, I.D. Flitcroft, E.T. Kanemasu, D. Nie, KF. Bronson, and H.U. Neue. 1995. Tunable laser diode measurements of methane fluxes from an irrigated rice paddy field in the Philippines. J. Geophys. Res. 100(D4):7283-7290.

Sutton, M.A., C. Milford, U. Dragosits, R. Singles, D. Fowler, C. Ross, R. Hill, S.C. Jarvis, B.F. Pain, R. Harrison, D. Moss, J. Webb, S.K. Espenhahn, C. Halliwell, D.S. Lee, G.P. Wyers, J. Hill, and H.M. ApSimon. 1997. Gradients of atmospheric ammonia concentrations and deposition downwind of ammonia emissions: First results of the ADEPT Burrington Moor experiment. p. 131-139. In S.C. Jarvis and B.P. (Ed.) Gaseous exchange with grassland systems. CAB Int.,

Sutton, M.A.., C. Milford, E. Nemitz, M.R. Theobald, P.W. Hill, D. Fowler, J.K. Schjoerring, M.E. Mattsson, K.H. Nielsen, S. Husted, J.W. Erisman, R. Otjes, A. Hensen, J. Mosquera, P. Celler, B. Loubet, M. David, S. Genermont, A. Neftel, A. Blatter, B. Gerrmann, S.K. Jones, L. Horvath, E.C. Fuhrer, K. Mantzannas, Z. Koukoura, M. Gallager, P. Williams, M. Flynn, and M. Riedo. 2001. Biosphere-atmosphere interactions of ammonia with grasslands: Experimental strategy and results from a new European initiative. Plant Soil 228:131-145.

Sutton, M.A., E. Nemitz, C. Milford, D. Fowler, J. Moreno, R. San Jose, G.P. Wyers, R.P Otjes, R. Harrison, S. Husted, and J.K. Schjoerring. 2000a. Micrometeorological measurements of net ammonia fluxes over oilseed rape during two vegetation periods. Agric. For. Meteorol. 2889:1-19.

Thompson, R.B., and J.J. Meisinger. 2002. Management factors affecting ammonia volatilization from land-applied cattle slurry in the Mid Atlantic USA. J. Environ. Qual. 31:1329-1338.

Todd, L.A., M.Ramanathan, K. Mottus, R. Katz, A. Dodson, and G. Mihlan. 2001. Measuring chemical emissions using open-path Fourier transform infrared (OP-FTIR) spectroscopy and computer-assisted tomography. Atmos. Environ. 35:1937-1947.

Vallis, I., L.A. Harper, V.R. Catchpoole, and K.L. Weier. 1982. Volatilization of ammonia from urine patches in a subtropical pasture. Aust. J. Agric. Res. 33:97-107.

Van Breeman, N., P.A. Burrough, E.J. Velthorst, H.F. Van Dobben, T. De Wit, T.B Ridder, and H.F.R. Reijnders. 1982. Soil acidification from ammonium sulphate in forest canopy throughfall. Nature 299:548-550.

Van der Eerden, L. 1982. Toxicity of ammonia to plants. Agric. Environ. 7:223-235.

Van der Hoek, K.W. 1998. Estimating ammonia emission factors in Europe: Summary of the work of the UNECE Ammonia Expert Panel. Atmos. Environ. 32:315-316.

Van der Hoek, K.W., and S. Couling. 1995. Manure management. Part 10. Agriculture and Forestry. Atmospheric Emissions Inventory Guidebook. 1st ed. CORINAIR/EMED, European Environ. Agency, Copenhagen, Denmark.

Voorburg, J.H., and G.J. Monteny. 1991. Emissions of $\mathrm{NH}_{3}$. Studies Environ. Sci. 46:217-238.

Wagner-Riddle, C., G.C. Edwards, and G.W. Thurtell. 2005. Trace gas concentration measurements for micrometeorological flux quantification. p. 301-324. In J.L. Hatfield and J.M. Baker (ed.) Micrometeorology in agricultural systems. ASA Monogr. 47. ASA, CSSA, and SSSA, Madison, WI (this volume).

Wagner-Riddle, C., G.W. Thurtell, K.M. King, G.E. Kidd, and E.G. Beauchamp. 1996. Nitrous oxide and carbon dioxide fluxes from a bare soil using a micrometeorological approach. J. Environ. Qual 25:898-907.

Warland, J.S., G.M. Dias, and G.W. Thurtell. 2001. A tunable diode laser system for ammonia flux measurements over multiple lots. Environ. Pollut. 114:215-221.

Warn, T.E., S. Aelmanowitz, and M. Saeger. 1990. Development and selection of ammonia emission factors for the 1985 emissions inventory. Rep. USEPA-600/7-90-014. USEPA, Washington, DC.

Weier, K.L., V.R. Catchpoole, and L.A. Harper. 1980. An automated colorimetric method for the determination of small concentrations of ammonia in dilute acid solution. Trop. Agron. Tech. Mem. no. 20. Div. Trop. Crops and Past. CSIRO, St. Lucia, Australia.

Wilson, J.D., V.R. Catchpoole, O.T. Denmead, and G.W. Thurtell. 1983. Verification of a simple micrometeorological method for estimating the rate of gaseous mass transfer from the ground to the atmosphere. Agric. Meteorol. 29:183-189.

Wilson, J.D., T.K. Flesch, and L.A. Harper. 2001. Micrometeorological methods for estimating surface exchange with a disturbed airflow. Agric. For. Meteorol. 107:207-225.

Wilson, J.D., G.W. Thurtell, G.E. Kidd, and E.G. Beauchamp. 1982. Estimation of the rate of gaseous mass transfer from a surface source plot to the atmosphere. Atmos. Environ. 16:1861-1867.

Wright, J.L., and E.R. Lemon. 1966. Photosynthesis under field conditions. 8. Analysis of windspeed fluctuation data to evaluate turbulent exchange within a corn crop. Agron. J. 58:255-261. 
Wyers, G.P., R.P. Otjes, and J. Slanina. 1993. A continuous-flow denuder for the measurements of ambient concentrations and surface-exchange fluxes of ammonia. Atmos. Env. 27A:20852090.

Zhang, R.H., D.L. Day, L.L. Christianson, and W.P. Jepson. 1994. A computer model for predicting ammonia release rates from swine manure pits. J. Agric. Eng. Res. 58:223-229.

Zhu, T., R.L. Desjardins, J.I MacPherson, E. Pattey, and G. St.-Amour. 1999. Aircraft-based volatile organic compounds flux measurements with relaxed eddy accumulation. Atmos. Environ. 33:1969-1979.

Zhu, T., E. Pattey, and R.L. Desjardins. 2000. Relaxed eddy-accumulation technique for measuring ammonia volatilization. Environ. Sci. Technol. 34:199-203. 